\title{
Síntese, caracterização e aplicação do trióxido de molibdênio na fotocatálise de efluente têxtil sintético
}

\section{(Synthesis, characterization and application of molybdenum trioxide in photocatalysis of synthetic textile effluent)}

\author{
C. A. A. Silva ${ }^{1}$, C. F. Silva ${ }^{1}$, J. M. E. Matos ${ }^{1,2 *}$ \\ ${ }^{1}$ Universidade Federal do Piauí, Centro de Tecnologia, Programa de Pós-Graduação em Ciências dos Materiais, \\ 64049-550, Teresina, PI, Brasil \\ ${ }^{2}$ Universidade Federal do Piauí, Centro de Ciências da Natureza, Programa de Pós-Graduação em Química, \\ Departamento de Química, Teresina, PI, Brasil
}

\begin{abstract}
Resumo
Neste estudo o trióxido de molibdênio $\left(\mathrm{MoO}_{3}\right)$ foi sintetizado pelo método hidrotérmico com temperatura fixa em $180{ }^{\circ} \mathrm{C}$ nos tempos de 1 e $6 \mathrm{~h}$, seguido de tratamento térmico por 6 e $12 \mathrm{~h}$ a 300,450 e $600{ }^{\circ} \mathrm{C}$. A fase cristalina e as propriedades estruturais da amostra foram caracterizadas pelo método de difração de raios X. O comportamento vibracional das ligações químicas foi verificado por espectroscopias na região do infravermelho e Raman, em que as bandas e picos observados confirmaram a formação do $\mathrm{MoO}_{3}$. $\mathrm{A}$ microscopia eletrônica de varredura mostrou a formação de microestruturas da fase hexagonal $\left(\mathrm{h}-\mathrm{MoO}_{3}\right)$ e ortorrômbica $\left(\alpha-\mathrm{MoO}_{3}\right)$ do $\mathrm{MoO}_{3}$. Além disso, as propriedades de absorção óptica foram medidas por espectroscopia de reflectância difusa e os valores de energia de gap foram estimados no intervalo de 2,74 a 3,33 eV a partir da função Kubelka-Munk. Os óxidos calcinados a $600{ }^{\circ} \mathrm{C}$ foram os que apresentaram a melhor atividade fotocatalítica, degradando $50 \%$ do corante em 2 h de reação.

Palavras-chaves: efluente sintético, fotocatálise, trióxido de molibdênio.
\end{abstract}

\begin{abstract}
In this study, the molybdenum trioxide $\left(\mathrm{MoO}_{3}\right)$ was synthetized by hydrothermal method with fixed temperature of $180{ }^{\circ} \mathrm{C}$ and different times of 1 and $6 \mathrm{~h}$, followed by heat treatment for 6 and $12 \mathrm{~h}$ at 300,450 and $600{ }^{\circ} \mathrm{C}$. The crystalline phase and structural properties of the sample were characterized by X-ray diffraction method. Vibrational behavior of chemical bonds was verified by infrared and Raman spectroscopies where the observed bands and peaks confirmed the formation of MoO ${ }_{3}$. The scanning electron microscopy showed the microstructure formation of hexagonal $\left(\mathrm{h}-\mathrm{MoO}_{3}\right)$ and orthorhombic $\left(\alpha-\mathrm{MoO}_{3}\right)$ phases. Furthermore, diffuse reflectance spectroscopy measured the optical absorption properties and the energy gap values were estimated in the range from 2.74 to $3.33 \mathrm{eV}$ from the Kubelka-Munk function. The oxides calcined at $600{ }^{\circ} \mathrm{C}$ showed the best photocatalytic activity, degrading $50 \%$ of dye in 2 h of reaction.

Keywords: synthetic effluent, photocatalysis, molybdenum trioxide.
\end{abstract}

\section{INTRODUÇÃO}

A poluição ambiental tem sido apontada como um dos maiores problemas enfrentados por vários países e, em particular, a progressiva contaminação das reservas aquíferas como consequências do crescimento global [1]. A indústria têxtil em particular utiliza elevada demanda de água em seus processos, gerando grande quantidade de águas residuárias com diversos compostos tóxicos, tais como sais dissolvidos, surfactantes, sólidos suspensos e matéria orgânica, principalmente na forma de moléculas corantes complexas [2]. Estes compostos, na maioria dos casos, são tratados por meio de processos biológicos, de extração e adsorção. Entretanto, tais técnicas apresentam limitações em sua aplicação em meio de concentrações elevadas, na presença de multicom-

*jmematos@ufpi.edu.br ponentes orgânicos, além do elevado custo de tratamento [3, 4]. Atualmente, os processos oxidativos avançados (POAs) têm se tornado uma das principais tecnologias para remediação e tratamento de águas, em vista de sua eficiência na degradação de poluentes orgânicos. Diferente de outros métodos utilizados, os POAs se caracterizam pela capacidade de formar radicais hidroxila (HO'), capazes de reagir com inúmeros compostos orgânicos promovendo sua mineralização para compostos inócuos como $\mathrm{CO}_{2}$ e água $[5,6]$.

Trabalhos sistemáticos sobre a remoção de corantes em efluentes têxteis têm sido propostos por diversos pesquisadores, no qual é demostrado ser possível a completa degradação desses contaminantes com a utilização de um fotocatalisador no processo [7, 8]. Entretanto, fotocatalisadores em sua maioria são óxidos semicondutores com valor elevado de band gap gerando rendimentos limitados, haja vista que valores elevados de band gap, 
por exemplo $\beta-\mathrm{Ga}_{2} \mathrm{O}_{3}(4,9 \mathrm{eV})$ e $\mathrm{Al}_{2} \mathrm{O}_{3}(8,8 \mathrm{eV})$, podem dificultar a transferência de energia da banda de condução para a banda de valência, impossibilitando sua aplicação como por exemplo em fotocatálise [9, 10]. Nesse sentido a pesquisa de novos materiais semicondutores capazes de degradar com mais eficiência tem sido alvo de interesse de muitos pesquisadores em todo mundo. Dentro desse contexto destaca-se o $\mathrm{MoO}_{3}$ com band gap de no máximo 3,3 eV [7,8, 11-16]. Nesse contexto o estudo sobre o $\mathrm{MoO}_{3}$ vem atraindo cada vez mais a atenção de pesquisadores em virtude de sua variedade de estruturas, características físico-químicas e seu leque de aplicações, no qual se destaca o uso em catálise [11], baterias [12], sensores de gás [13], tecnologias para dispositivos eletrocrômicos [14, 15] e fotodegradação [16].

$\mathrm{O} \mathrm{MoO}_{3}$ é conhecido por apresentar vários polimorfos, que são divididos em cinco fases: uma fase ortorrômbica $\alpha-\mathrm{MoO}_{3}$ termodinamicamente estável [17], quatro fases metaestáveis, sendo três monoclínicas $\beta-\mathrm{MoO}_{3}[18], \mathrm{MoO}_{3}$-II [19] e $\mathrm{MoO}_{3}$-III [20], e uma hexagonal h- $\mathrm{MoO}_{3}$, além das fases de $\mathrm{MoO}_{3}$ hidratadas, com fórmula geral $\mathrm{MoO}_{3} \cdot \mathrm{nH}_{2} \mathrm{O}$. A obtenção da fase particular do óxido de molibdênio micro e nanoestruturado é altamente dependente do processo de síntese e das condições de crescimento [21]. A literatura descreve diversos métodos, tais como pulverização [22], evaporação térmica [23], deposição de vapor químico (CVD) [24], sol-gel [25] e hidrotérmico [26]. O molibdênio é encontrado em várias estequiometrias de óxido, que são empregadas em diferentes pesquisas de alto valor e aplicações comerciais [27]. As características químicas e físicas dos óxidos de molibdênio os tornam versáteis e altamente ajustáveis para incorporação em sistemas ópticos, eletrônicos, catalíticos, biológicos e energéticos [27]. As variações nos estados de oxidação permitem a manipulação da estrutura de cristal, morfologia, vacância de oxigênio e dopantes, para controlar a engenharia de estados eletrônicos. Apesar desta funcionalidade e alto potencial de aplicação, pesquisas que visam a obtenção e aplicação do $\mathrm{MoO}_{3}$ não estão esgotadas. Assim, este trabalho tem por objetivo a síntese do $\mathrm{MoO}_{3}$ pelo método hidrotérmico seguido de calcinação, caracterização e aplicação como catalisador no processo de fotocatálise heterogênea em efluente têxtil sintético para avalição de sua atividade fotocatalítica.

\section{EXPERIMENTAL}

Síntese do trióxido de molibdênio: o trióxido foi produzido a partir da pesagem de 7,00 g do precursor heptamolibdato de amônio $\left[\left(\mathrm{NH}_{4}\right)_{6} \mathrm{Mo}_{7} \mathrm{O}_{24}\right.$, Sigma-Aldrich, 99\%], em balança analítica. Em seguida foi dissolvido em $70 \mathrm{~mL}$ de água deionizada com agitação. $\mathrm{O}$ pH da solução foi ajustado cuidadosamente com ácido acético glacial $\left(\mathrm{CH}_{3} \mathrm{COOH}\right.$, Impex, 98\%) até o valor de 3,5. A solução foi colocada em autoclave de aço inox e submetida à reação hidrotérmica a $180{ }^{\circ} \mathrm{C}$ por 1 e $6 \mathrm{~h}$, obtendo ao final um precipitado separado do sobrenadante por filtração. $\mathrm{O}$ precipitado formado foi submetido a aquecimento em estufa a $100{ }^{\circ} \mathrm{C}$ para evaporação do líquido e obtenção do
Tabela I - Composição do efluente sintético. [Table I - Composition of the synthetic effluent.]

\begin{tabular}{cc}
\hline Componente & Concentração $\left(\mathrm{g} . \mathrm{L}^{-1}\right)$ \\
\hline Corante preto direto & 0,10 \\
Álcool polivinílico & 0,50 \\
$\mathrm{NaCl}$ & 0,25 \\
$\mathrm{Na}_{2} \mathrm{SO}_{4}$ & 0,75 \\
\hline
\end{tabular}

precipitado branco. Os precipitados foram separados e submetidos ao processo de calcinação em mufla a 300,450 e $600{ }^{\circ} \mathrm{C}$ por 6 e $12 \mathrm{~h}$ e posteriormente caracterizados.

Caracterização do trióxido de molibdênio: os óxidos obtidos foram caracterizados por difração de raios X (DRX), em difratômetro Rigaku, Geigerflex à temperatura ambiente com radiação $\mathrm{CuK} \alpha(\lambda=1,5406 \AA)$. A análise foi realizada com passo de $0,02^{\circ}$ no intervalo de $5^{\circ}$ a $75^{\circ}(2 \theta)$ a $0,5^{\circ} / \mathrm{min}$ em modo contínuo. Os espectros na região do infravermelho (FTIR) para os materiais sintetizados foram obtidos em um espectrofotômetro Vertex 70 da Bruker. A análise foi realizada na região de 4000 até $400 \mathrm{~cm}^{-1}$ com resolução de $4 \mathrm{~cm}^{-1}$ usando mistura sólida com KBr. Os espectros Raman foram obtidos por meio do espectrofotômetro Raman confocal da Bruker, Senterra, utilizando uma linha laser em $532 \mathrm{~nm}$ com resolução de $3,5 \mathrm{~cm}^{-1}$ na faixa de $85-1550 \mathrm{~cm}^{-1}$. A morfologia dos óxidos foi investigada por microscopia eletrônica de varredura com fonte de elétrons de emissão por campo (MEV-EC), utilizando um equipamento FEI, Quanta 200 FEG. Os espectros de reflectância difusa foram obtidos após compactação dos pós tendo o sulfato de bário como referência nessa análise. A varredura foi realizada em comprimentos de onda de 200 a $800 \mathrm{~nm}$. As propriedades texturais foram determinadas a partir das isotermas de adsorção de nitrogênio registradas em $77 \mathrm{~K}$ com um aparelho Quantachrome Nova 4200. As amostras foram desgaseificadas em vácuo a $423 \mathrm{~K}$ durante $15 \mathrm{~h}$ afim de manter a superfície limpa e seca. As áreas específicas das amostras (BET) foram calculadas medindo-se a massa da monocamada de nitrogênio adsorvida em função da pressão relativa no intervalo de equilíbrio de $0,0<\mathrm{P} / \mathrm{P}_{0}<1,0$. $\mathrm{O}$ volume e o diâmetro de poros foram determinados pelo método do algoritmo BJH (Barret-Joyner-Halenda) a partir das isotermas de adsorção e dessorção.

Preparação do efluente têxtil sintético: o efluente têxtil sintético formado por corante preto direto (Basf, 100\%), álcool polivinílico (88\% hidrolisado, Sigma-Aldrich), $\mathrm{NaCl}$ (Sigma-Aldrich, 99,5\%) e $\mathrm{Na}_{2} \mathrm{SO}_{4}$ (Sigma-Aldrich, 99\%) foi preparado de acordo com o proposto em [28] nas concentrações contidas na Tabela I. Esse corante foi escolhido por ser bastante utilizado nas indústrias têxteis da cidade de Teresina, Piauí, e por ser considerado de difícil remoção pela indústria.

Estruturas do sistema de reação: a unidade reacional (Fig. 1) consistiu de um reator de vidro com capacidade para $500 \mathrm{~mL}$ com sistema de refrigeração por meio da circulação de água, aeração com borbulhamento de ar, agitação 


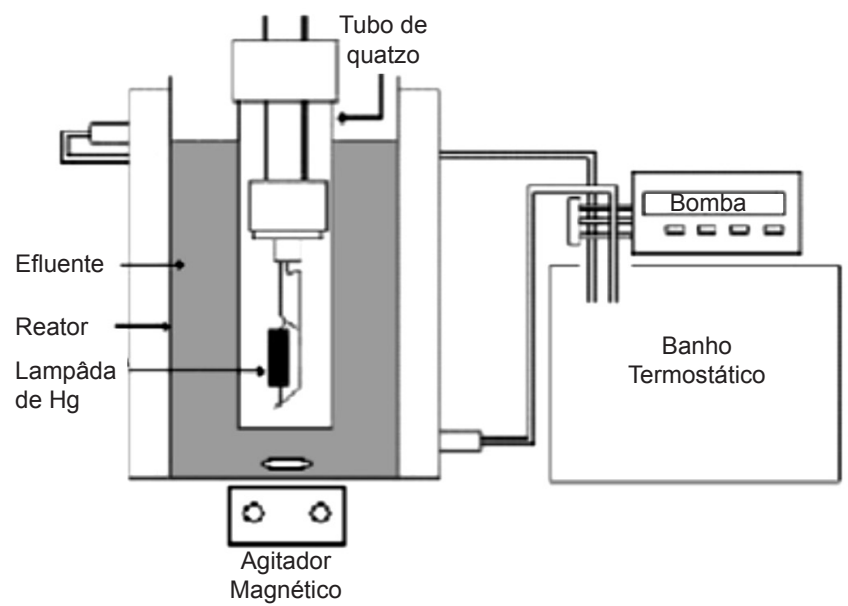

Figura 1: Esquema ilustrativo do reator de fotocatálise.

[Figure 1: Illustrative scheme of photocatalyst reactor.]

magnética e irradiação com lâmpada de vapor de mercúrio de alta pressão de $125 \mathrm{~W}$, encapsulada em um tubo de quartzo. Essa unidade encontrava-se no interior de uma caixa protetora. $\mathrm{O}$ procedimento experimental consistiu na irradiação de $350 \mathrm{~mL}$ do efluente têxtil sintético com $0,35 \mathrm{~g}$ do $\mathrm{MoO}_{3}$. A lâmpada ficou imersa no efluente e a homogeneidade da solução foi mantida por intermédio de um agitador magnético e a manutenção das condições isotérmicas em torno de $25 \pm 2{ }^{\circ} \mathrm{C}$ foi estabelecida por meio de um banho de circulação de água. Foram coletadas alíquotas de $3 \mathrm{~mL} \mathrm{em}$ intervalos regulares $(30,60,90$ e $120 \mathrm{~min})$, centrifugadas e analisadas em espectrofotômetro. A percentagem de descoloração foi determinada usando um espectrofotômetro UVvisível (UV-Femto 600 plus v.2.4), fazendo-se a leitura de absorbância no comprimento de onda de absorção máxima do efluente sintético $\left(\lambda_{\max }=484 \mathrm{~nm}\right)$.

\section{RESULTADOS E DISCUSSÃO}

$\mathrm{O}$ mecanismo de formação do $\mathrm{MoO}_{3}$ está associado à reação do precursor heptamolibdênio de amônio, $\left(\mathrm{NH}_{4}\right)_{6} \mathrm{Mo}_{7} \mathrm{O}_{24}$, com o ácido acético. Inicialmente, na etapa de síntese hidrotérmica (Eqs. A a C), teve-se a dissociação do $\left(\mathrm{NH}_{4}\right)_{6} \mathrm{Mo}_{7} \mathrm{O}_{24}$ formando os íons de amônio $\left(\mathrm{NH}_{4}^{+}\right)$e isopolimolibdato $\left(\mathrm{Mo}_{7} \mathrm{O}_{24}{ }^{6-}\right)$, conforme Eq. A. Em seguida o meio foi acidificado com ácido acético, formando as espécies descritas na Eq. B. Em seguida, a solução foi submetida a aquecimento $\left(<75^{\circ} \mathrm{C}\right)$, formando o $7\left(\mathrm{NH}_{4}\right)_{2} \mathrm{O} .4\left(\mathrm{MoO}_{3}\right)_{7}$ (Eq. C). Conforme a temperatura se elevou $\left(<250{ }^{\circ} \mathrm{C}\right)$ na etapa de calcinação (Eqs. D a F), teve-se a formação do $\mathrm{MoO}_{3}$ puro com a perda do $7\left(\mathrm{NH}_{4}\right)_{2} \mathrm{O}$ (Eq. D); acetato de amônio, amônia e ácido acético se decompõem em altas temperaturas (Eqs. E e F).

$$
\begin{aligned}
& 4\left(\mathrm{NH}_{4}\right)_{6} \mathrm{Mo}_{7} \mathrm{O}_{24(\mathrm{~s})}+5 \mathrm{H}_{2} \mathrm{O}_{(1)} \rightarrow \\
& 4 \mathrm{Mo}_{7} \mathrm{O}_{24}{ }^{6-}+24 \mathrm{NH}_{4}^{+}+5 \mathrm{H}_{2} \mathrm{O}_{(1)} \\
& 4 \mathrm{Mo}_{7} \mathrm{O}_{24}{ }^{6-}+24 \mathrm{NH}_{4}^{+}+5 \mathrm{H}_{2} \mathrm{O}_{(1)}+15 \mathrm{CH}_{3} \mathrm{COOH} \rightarrow \\
& 7 \mathrm{Mo}_{4} \mathrm{O}_{13}{ }^{2-}+5 \mathrm{H}^{+}+24 \mathrm{NH}_{4}^{+}+15 \mathrm{CH}_{3} \mathrm{COO}^{-}+10 \mathrm{H}_{2} \mathrm{O}
\end{aligned}
$$

$$
\begin{aligned}
& 7 \mathrm{Mo}_{4} \mathrm{O}_{13}{ }^{2-}+5 \mathrm{H}^{+}+24 \mathrm{NH}_{4}{ }^{+}+15 \mathrm{CH}_{3} \mathrm{COO}^{-}+ \\
& 5 \mathrm{H}_{2} \mathrm{O} \stackrel{\unlhd}{\leftrightarrows} 7\left(\mathrm{NH}_{4}\right)_{2} \mathrm{O} .4\left(\mathrm{MoO}_{3}\right)_{7} \downarrow+ \\
& 10\left(\mathrm{NH}_{4}\right) \mathrm{Ac}_{(\mathrm{aq})}+5 \mathrm{HAc}_{(\mathrm{aq})}+5 \mathrm{H}_{2} \mathrm{O}_{(\mathrm{l})}
\end{aligned}
$$

$7\left(\mathrm{NH}_{4}\right)_{2} \mathrm{O} .4\left(\mathrm{MoO}_{3}\right)_{7} \downarrow+10\left(\mathrm{NH}_{4}\right) \mathrm{Ac}_{(\mathrm{aq})}+5 \mathrm{HAc}_{(\text {aq) }}+$ $5 \mathrm{H}_{2} \mathrm{O}_{(\mathrm{I})} \triangle 28 \mathrm{MoO}_{3(\mathrm{~s})}+14 \mathrm{NH}_{3} \uparrow+10\left(\mathrm{NH}_{4}\right) \mathrm{Ac} \uparrow+$ $5 \mathrm{HAc} \uparrow+12 \mathrm{H}_{2} \mathrm{O} \uparrow$

$\mathrm{CH}_{3} \mathrm{COOH}+2 \mathrm{O}_{2} \rightarrow 2 \mathrm{CO}_{2}+2 \mathrm{H}_{2} \mathrm{O}$

$4 \mathrm{NH}_{3}+5 \mathrm{O}_{2} \rightarrow 4 \mathrm{NO}+6 \mathrm{H}_{2} \mathrm{O}$

Caracterização estrutural: a estrutura cristalina das amostras sintetizadas foi caracterizada por DRX. As principais reflexões foram identificadas com auxílio dos arquivos cristalográficos adquiridos no banco de dados ICSD (Inorganic Crystal Structure Database), referentes às fases ortorrômbica e hexagonal do $\mathrm{MoO}_{3}$. Inicialmente foram caracterizadas as amostras sem tratamento térmico, de modo a estabelecer um parâmetro acerca da estrutura do material formado após a síntese hidrotérmica, Fig. 2. $\mathrm{O}$ óxido obtido hidrotermicamente em $1 \mathrm{~h}$ apresentou planos característicos do $\mathrm{MoO}_{3}$, sendo possível identificar a formação da fase $\mathrm{h}-\mathrm{MoO}_{3}$ (hexagonal) juntamente com a fase $\alpha-\mathrm{MoO}_{3}$ (ortorrômbica), por meio da formação dos planos característicos nas regiões destacadas. No entanto, foi possível observar, em acordo com a literatura [29], que este tempo não foi suficiente para a formação do óxido, haja visto que ainda existiu material de partida. No difratograma do óxido obtido em $6 \mathrm{~h}$ de síntese teve-se um aumento da intensidade dos planos das fases hexagonal e ortorrômbica, mostrando-se mais efetivo que o tempo de $1 \mathrm{~h}$. No entanto, ainda foi possível observar a existência de material de partida. Dessa forma, verificou-se a necessidade da aplicação do tratamento térmico, com vista a promover a transição das fases para estrutura de fase única, além de volatilizar moléculas ligadas ao cristal e água de cristalização.

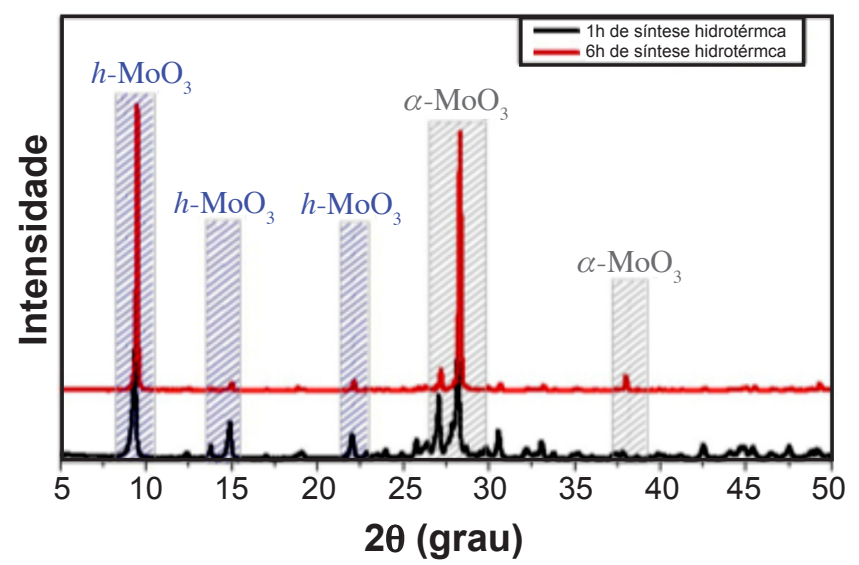

Figura 2: Difratogramas de raios $\mathrm{X}$ das amostras sintetizadas a $180{ }^{\circ} \mathrm{C}$ por 1 e $6 \mathrm{~h}$ sem tratamento térmico.

[Figure 2: X-ray diffraction patterns of samples synthesized at $180^{\circ} \mathrm{C}$ for 1 and $6 \mathrm{~h}$ without heat treatment.] 
Na Fig. 3a têm-se os espectros de DRX das amostras de $\mathrm{MoO}_{3}$ sintetizadas a $180^{\circ} \mathrm{C}$ por 1 e $6 \mathrm{~h}$ e calcinadas à temperatura de $300{ }^{\circ} \mathrm{C}$ por 6 e $12 \mathrm{~h}$. Observou-se a presença da fase h- $\mathrm{MoO}_{3}$ (denominada $\mathrm{h}$ ) identificada pelos planos característicos (100), (110) e (200), assim como a fase $\alpha-\mathrm{MoO}_{3}$ (denominada $\alpha$ ) com seus principais planos (020), (040), (021) e (060), conforme arquivos-padrão ICSD no 21-0509 e 35076, respectivamente. Com relação às variáveis tempo e temperatura, o padrão de reação hidrotérmica adotado de $180^{\circ} \mathrm{C}$ favoreceu a formação de cristais de $\mathrm{MoO}_{3}$ com mistura de fase. Em relação ao tempo não foram observadas alterações significativas entre 1 e $6 \mathrm{~h}$. Quanto ao processo de calcinação as variáveis tempo e temperatura foram determinantes para obtenção do produto final com alta cristalinidade. As amostras calcinadas por $12 \mathrm{~h}$ apresentaram melhor singularidade de fase, com predominância da estrutura ortorrômbica. Quanto a $300^{\circ} \mathrm{C}$ notou-se que houve apenas uma transformação parcial da fase metaestável h- $\mathrm{MoO}_{3}$ para $\alpha-\mathrm{MoO}_{3}$ mais estável. De acordo com [30,31], as transformações de fases são favorecidas na seguinte hierarquia: $\mathrm{MoO}_{3}$ amorfo $<\beta-\mathrm{MoO}_{3}$ monoclínico $<\mathrm{h}-\mathrm{MoO}_{3}$ hexagonal $<$ $\alpha-\mathrm{MoO}_{3}$ ortorrômbico. Os resultados do $\mathrm{MoO}_{3}$ calcinado a $450^{\circ} \mathrm{C}$ são mostrados na Fig. 3b. Os difratogramas mostraram claramente os planos característicos do $\alpha-\mathrm{MoO}_{3}$, bem como ausência de planos de outras fases. Os tempos de síntese e calcinação não produziram alterações significativas. Com relação à temperatura de calcinação, podese afirmar que estas condições de reação foram suficientes para a completa formação da fase $\alpha-\mathrm{MoO}_{3}$. Na Fig. 3c tem-se o $\mathrm{MoO}_{3}$ calcinado a $600{ }^{\circ} \mathrm{C}$. Os planos $(0 \mathrm{~b} 0) \mathrm{com}$ $\mathrm{b}=2,4$ e 6 , ou seja (020), (040) e (060), apresentaram forte intensidade em comparação com os dados do arquivo ICSD, indicando a orientação preferencial das partículas ao longo do eixo b, resultado de um crescimento anisotrópico do material, concordante com o exposto em [32].

Os produtos formados mostraram que os cristais de $\mathrm{MoO}_{3}$ apresentaram forte crescimento preferencial nos planos (020) e (040) em comparação com o arquivo padrão, o qual apresenta menor intensidade para esses planos. Notou-se que à medida que a temperatura de calcinação aumentou de 450 para $600{ }^{\circ} \mathrm{C}$ a intensidade dos planos (020) e (040) acompanhou esse crescimento. O tratamento térmico produziu alterações nas intensidades relativas e/ou na largura dos picos, mas não em suas posições, ou seja, estas alterações foram consequências da mudança de morfologia e/ou o tamanho dos cristalitos, mas não da estrutura cristalina [33]. A análise ampliada dos difratogramas do $\mathrm{MoO}_{3}$ calcinado a 300,450 e $600{ }^{\circ} \mathrm{C}$ mostrou um deslocamento na posição de alguns planos para um maior ângulo 20. Na Fig. 4 temse uma exemplificação desse fato, a partir da ampliação do plano (020) da Fig. 3c. Observa-se para valor de $2 \theta$ uma variação para um maior ângulo. De acordo com [26], este desvio pode ser causado em função de fatores como pressão de compressão do material no momento da compactação do pó, bem como mudanças no tamanho do cristal, forma e estequiometria da amostra. Os três últimos podem
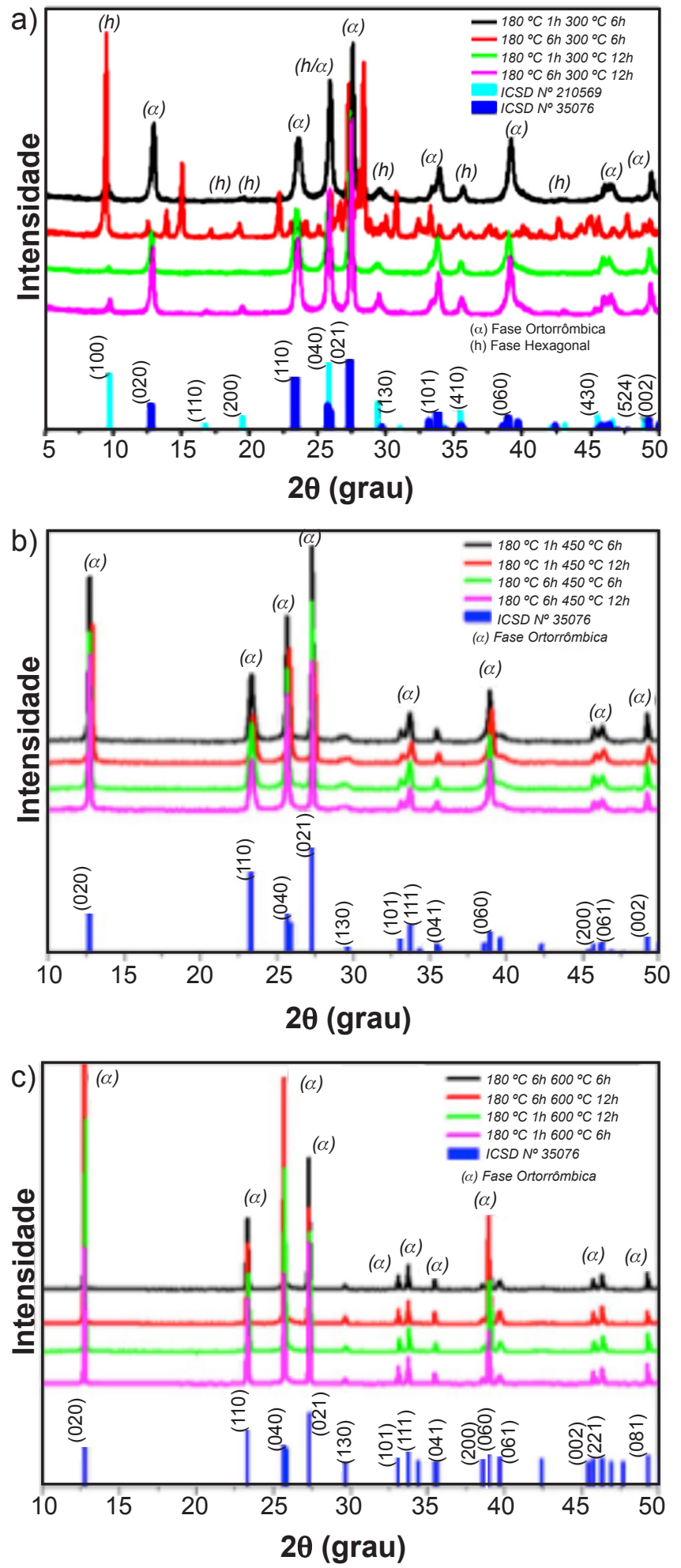

Figura 3: Difratogramas de raios $\mathrm{X}$ das amostras de $\mathrm{MoO}_{3}$ sintetizadas a $180{ }^{\circ} \mathrm{C}$ durante 1 e $6 \mathrm{~h}$ e calcinadas por 6 e $12 \mathrm{~h} \mathrm{a:} \mathrm{(a)} 300{ }^{\circ} \mathrm{C}$; (b) $450{ }^{\circ} \mathrm{C}$; e (c) $600{ }^{\circ} \mathrm{C}$.

[Figure 3: X-ray diffraction patterns of samples of $\mathrm{MoO}_{3}$ synthesized at $180^{\circ} \mathrm{C}$ for 1 and $6 \mathrm{~h}$ and calcined for 6 and $12 \mathrm{~h}$ at: (a) $300^{\circ} \mathrm{C}$; (b) $450^{\circ} \mathrm{C}$; and (c) $600^{\circ} \mathrm{C}$.]

ocorrer em função do método de síntese. No entanto esses fatores podem não apresentar consequência direta quanto à aplicação do material. 
Análise de infravermelho: de acordo com a teoria de grupos, 45 modos ópticos são esperados no centro da zona de Brillouin no ponto $\Gamma(0,0,0)$ para o grupo espacial $\mathrm{D}_{2 \mathrm{~h}}$, ao qual pertence o $\alpha-\mathrm{MoO}_{3}$. A decomposição dos modos vibracionais nas representações irredutíveis do grupo $D_{2 h}$ é dada por $\Gamma=8 \mathrm{~A}_{\mathrm{g}}+8 \mathrm{~B}_{1 \mathrm{~g}}+4 \mathrm{~B}_{2 \mathrm{~g}}+4 \mathrm{~B}_{3 \mathrm{~g}}+4 \mathrm{~A}_{\mathrm{u}}+3 \mathrm{~B}_{1 \mathrm{u}}+7 \mathrm{~B}_{2 \mathrm{u}}+7 \mathrm{~B}_{3 \mathrm{u}}$. Destes, 17 modos são ativos no infravermelho $\left(3 \mathrm{~B}_{1 \mathrm{u}}, 7 \mathrm{~B}_{2 \mathrm{u}}\right.$, $\left.7 \mathrm{~B}_{3 \mathrm{u}}\right), 24$ são ativos no Raman $\left(8 \mathrm{~A}_{\mathrm{g}}, 8 \mathrm{~B}_{1 \mathrm{~g}}, 4 \mathrm{~B}_{2 \mathrm{~g}}, 4 \mathrm{~B}_{3 \mathrm{~g}}\right)$ e 4 são inativos $\left(4 \mathrm{~A}_{\mathrm{u}}\right)$ [34]. Beattie e Gilson [35] descrevem separadamente as vibrações dos átomos de oxigênio ligados ao metal. Assim, têm-se os que se ligam a um único átomo de molibdênio [terminais $\mathrm{Mo}=\mathrm{O}(1)$ ], os que se ligam a dois átomos de molibdênio (Mo-O-Mo) e os que se ligam a três átomos de molibdênio [Mo(3)-O]. Em uma mesma subcamada, as unidades básicas se conectam por ligações covalentes e, entre camadas, por forças de van der Waals. $\mathrm{Na}$ Fig. 5 têm-se os espectros das amostras de $\mathrm{MoO}_{3}$ após 1 e 6 h de síntese hidrotérmica, não calcinadas. Observaramse bandas formadas nas regiões em torno de 3150 e 1404 $\mathrm{cm}^{-1}$ referente às vibrações de estiramento e deformação angular do grupo amina (-NH), respectivamente. As bandas nas regiões em torno de 3300 e $1618 \mathrm{~cm}^{-1}$ corresponderam às vibrações de estiramento e deformação angular das moléculas de água $(-\mathrm{OH})$. Na faixa entre 1000 a $500 \mathrm{~cm}^{-1}$ têm-se as bandas referentes às vibrações dos átomos de oxigênio ligados ao molibdênio, porém sem definição específica das bandas.

Na Fig. 6a têm-se os espectros das amostras do $\mathrm{MoO}_{3}$ calcinadas a $300{ }^{\circ} \mathrm{C}$ por 6 e $12 \mathrm{~h}$. As bandas localizadas na região de 3500 e $1628 \mathrm{~cm}^{-1}$ foram atribuídas a vibrações de estiramento e deformação angular das moléculas de água, respectivamente, enquanto as bandas detectadas na região de 3153 e $1410 \mathrm{~cm}^{-1}$ representam as vibrações do grupo $\mathrm{NH}_{4}^{+}$residual do $\mathrm{MoO}_{3}$, resultante do percursor. Estas observações são concordantes com relatos anteriores [3537]. Na região das vibrações de estiramento entre 1050 e $400 \mathrm{~cm}^{-1}$, foi possível distinguir três principais padrões de absorção característicos do $\mathrm{MoO}_{3}$ bem definidos em 995,850 e na região de $590 \mathrm{~cm}^{-1}$. A banda em $995 \mathrm{~cm}^{-1}$ foi atribuída

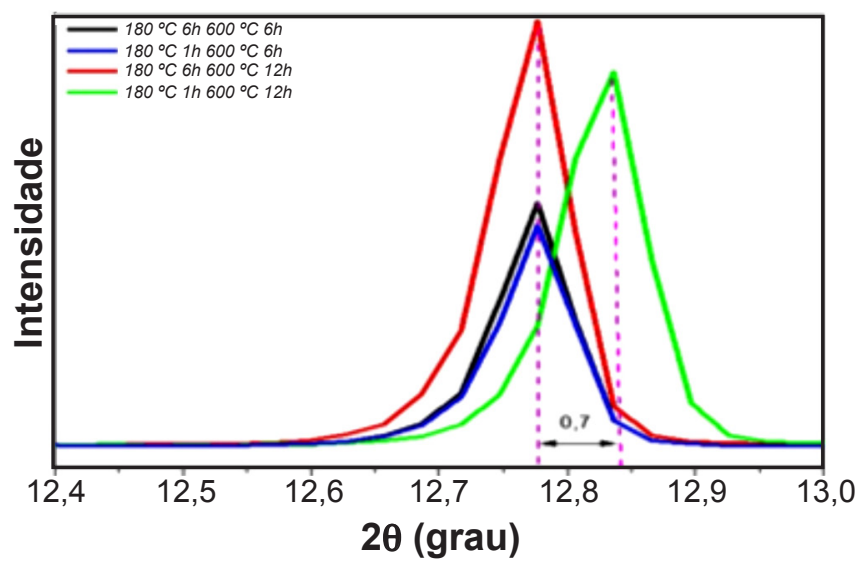

Figura 4: Ampliação da Fig. 3c mostrando variações na posição do pico.

[Figure 4: Magnification of Fig. 3c showing variations in the peak position.]

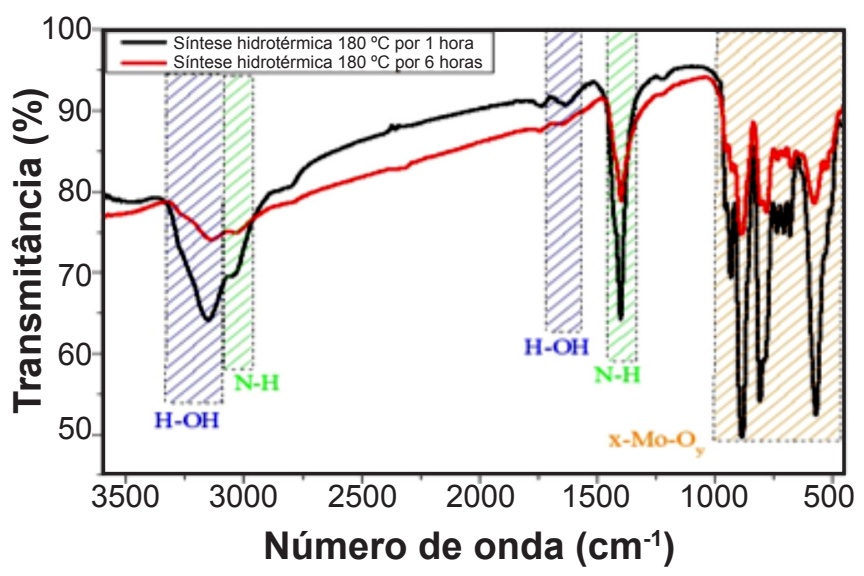

Figura 5: Espectros de infravermelho dos pós de $\mathrm{MoO}_{3}$ obtidos após reação hidrotérmica de 1 e $6 \mathrm{~h}$ (sem calcinação).

[Figure 5: Infrared spectra of $\mathrm{MoO}_{3}$ powders obtained after hydrothermal reaction of 1 and $6 \mathrm{~h}$ (without calcination).]

à ligação $(\mathrm{Mo}=\mathrm{O})$ terminal, indicando fase ortorrômbica em camadas do $\mathrm{MoO}_{3}$ [38]. A presença do pico em $850 \mathrm{~cm}^{-1}$ foi associada aos comprimentos de ligação simétrica entre o molibdênio e o oxigênio, resultante de dois octaedros $\left(\mathrm{MoO}_{6}\right)$ com oxigênios compartilhados pelos vértices. A banda na região de $590 \mathrm{~cm}^{-1}$ foi atribuída ao oxigênio triplamente coordenado [Mo-O(3)] [39]. O pico em $501 \mathrm{~cm}^{-1}$ foi atribuído ao modo de deformação (O-Mo-O) [40]. Nas Figs. $6 \mathrm{~b}$ e $6 \mathrm{c}$ tem-se em destaque a região compreendida entre 1200 e $400 \mathrm{~cm}^{-1}$ do $\mathrm{MoO}_{3}$ calcinado a 450 e 600 ${ }^{\circ} \mathrm{C}$, respectivamente. A região entre 4000 e $1200 \mathrm{~cm}^{-1}$ foi omitida por não apresentar absorções características de grupos associados ao $\mathrm{MoO}_{3}$. Na Fig. 6c os pós de $\mathrm{MoO}_{3}$ calcinados a $600{ }^{\circ} \mathrm{C}$ apresentaram as bandas características da fase $\alpha-\mathrm{MoO}_{3}$ em 991,855 e $555 \mathrm{~cm}^{-1}$ [41, 42]. O pico em $820 \mathrm{~cm}^{-1}$ refere-se a vibrações de deformação angular do oxigênio duplamente coordenado (Mo-O-Mo), ou seja, o que se liga a dois átomos de Mo [38], que resulta do átomo de oxigênio de canto, compartilhado com duas unidades octaédricas. Nas Figs. 6a a 6c na região entre 1050 a $400 \mathrm{~cm}^{-1}$, é possível identificar variações nas posições e larguras das bandas devido ao efeito de divisão longitudinal-transversal. As bandas são influenciadas em sua posição e largura por apresentarem diferentes tamanhos de cristalito e morfologias [33]. Em amostra de pós, tamanhos de cristalitos diferentes e/ou morfologias diferentes coexistem no mesmo material, de tal modo que duas bandas podem ser atribuídas para o mesmo modo de vibração [33].

Análise de Raman: os espectros Raman dos pós de $\mathrm{MoO}_{3}$ são mostrados nas Figs. 7 e 8 . Os picos intensos foram atribuídos à alta cristalinidade do material, sendo possível identificar os três principais picos $(994,818$ e 290 $\mathrm{cm}^{-1}$ ) característicos da estrutura ortorrômbica em camadas $[20,39,43]$. Na Fig. 7 têm-se os espectros referentes às amostras sintetizadas sem tratamento térmico. Com base na coordenação octaédrica dos átomos de molibdênio foram atribuídos os modos de vibrações para cada região do espectro Raman do $\mathrm{MoO}_{3}$. As três principais foram 1000 a $600 \mathrm{~cm}^{-1}, 400$ a $200 \mathrm{~cm}^{-1}$ e abaixo de $200 \mathrm{~cm}^{-1}$, 

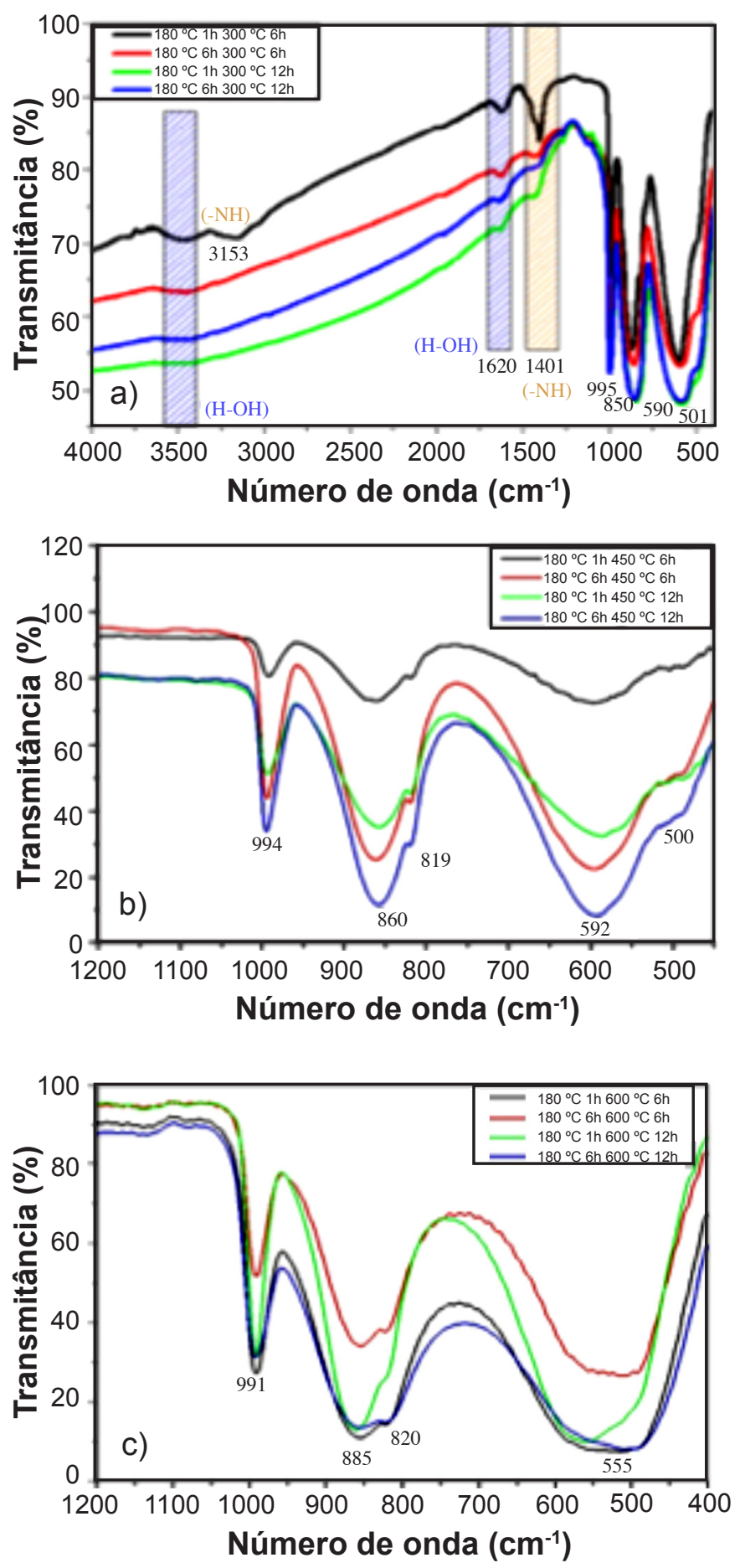

Figura 6: Espectros de infravermelho das amostras de $\mathrm{MoO}_{3}$ sintetizadas a $180{ }^{\circ} \mathrm{C}$ por 1 e $6 \mathrm{~h}$ e calcinadas por 6 e $12 \mathrm{~h}$ a: (a) $300{ }^{\circ} \mathrm{C}$; (b) $450{ }^{\circ} \mathrm{C}$; e (c) $600{ }^{\circ} \mathrm{C}$.

[Figure 6: Infrared spectra of the $\mathrm{MoO}_{3}$ samples synthesized at $180{ }^{\circ} \mathrm{C}$ for 1 and $6 \mathrm{~h}$ and calcined for 6 and $12 \mathrm{~h}$ at: (a) $300{ }^{\circ} \mathrm{C}$; (b) $450^{\circ} \mathrm{C}$; and (c) $600{ }^{\circ} \mathrm{C}$.]

que corresponderam a estiramento, deformação e modo translacional de rede, respectivamente [31]. A presença de picos na região de vibrações de estiramento indicou a formação da fase $\alpha-\mathrm{MoO}_{3}$ e a dependência do tratamento térmico sobre a estrutura cristalográfica final do $\mathrm{MoO}_{3}$.

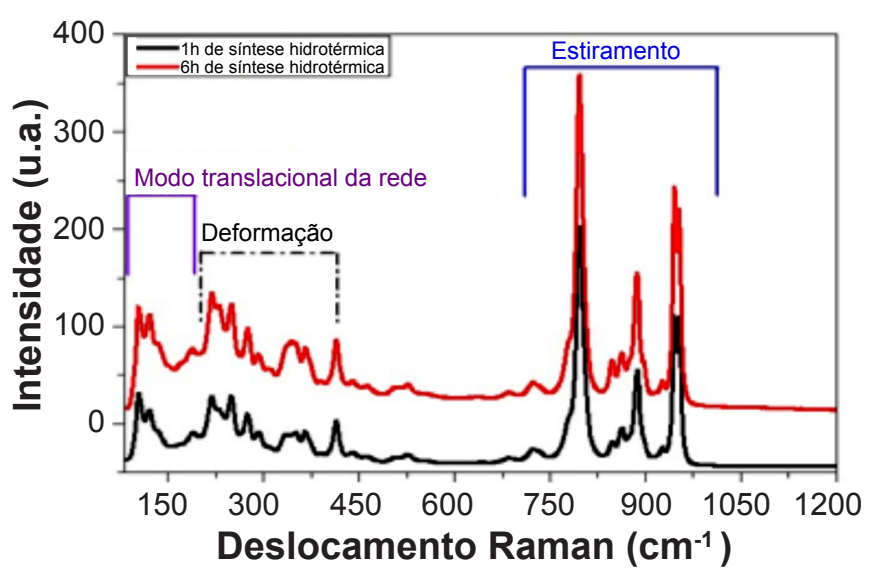

Figura 7: Espectros Raman das amostras de síntese hidrotérmica a $180{ }^{\circ} \mathrm{C}$ por 1 e $6 \mathrm{~h}$ sem calcinação.

[Figure 7: Raman spectra of the samples from hydrothermal synthesis at $180{ }^{\circ} \mathrm{C}$ for 1 and $6 \mathrm{~h}$ without calcination.]

Na Fig. 8a encontram-se os espectros Raman das amostras sintetizadas hidrotermicamente a $180{ }^{\circ} \mathrm{C}$ por 1 e $6 \mathrm{~h}$, seguidas de calcinação a $300{ }^{\circ} \mathrm{C}$ por 6 e 12 h. É possível notar que as amostras calcinadas por 6 e $12 \mathrm{~h}$ apresentaram picos características da fase ortorrômbica em 994, 818 e $665 \mathrm{~cm}^{-1}$ com algumas diferenças de intensidade. A análise vibracional observada nas Figs. 8 a e 8 b revela que o pico intenso e estreito posicionado em $994 \mathrm{~cm}^{-1}$ é atribuído a vibrações de alongamento do oxigênio terminal $(\mathrm{Mo}=\mathrm{O})$ ao longo das direções a e b, a partir do oxigênio não compartilhado, que são responsáveis pela estrutura em camadas do $\mathrm{MoO}_{3}$ [35]. O pico Raman em $818 \mathrm{~cm}^{-1}$ foi o pico mais intenso da fase $\alpha-\mathrm{MoO}_{3}$, que tem origem das vibrações de estiramento do oxigênio duplamente coordenado (MoO-Mo) ligado ao longo do eixo x [44]. Já o pico em 290 $\mathrm{cm}^{-1}$ foi atribuído à vibração wagging do $\mathrm{Mo}=\mathrm{O}=\mathrm{Mo} . \mathrm{O}$ pico situado em $665 \mathrm{~cm}^{-1}$ refere-se a vibrações de estiramento do oxigênio triplamente coordenado $[\mathrm{Mo}(3)-\mathrm{O})]$, que resulta do oxigênio de ponta compartilhado com três octaedros [45]. Em $470 \mathrm{~cm}^{-1}$ têm-se vibrações de deformação angular (Mo-O-Mo), 377, 367, 243, 215 e 195 cm$^{-1}$ (Mo-O-Mo), e vibrações do tipo scissor, $337 \mathrm{~cm}^{-1}$ (O-Mo-O) [46-48]. O pico Raman em $155 \mathrm{~cm}^{-1}$ foi devido a $(\mathrm{O}-\mathrm{Mo})_{\mathrm{n}}$, poliedros ao longo do eixo da cadeia [1]. Os espectros das amostras calcinadas a $450{ }^{\circ} \mathrm{C}$ (Fig. 8b) e $600{ }^{\circ} \mathrm{C}$ (Fig. 8c) apresentaram comportamentos semelhantes; o aumento da temperatura contribuiu para o aumento da cristalinidade e formação da fase $\alpha-\mathrm{MoO}_{3}$. De acordo com [34], nos espectros Raman na maioria das vezes os efeitos mais pronunciados quanto ao aumento de temperatura são: a) deslocamento das linhas Raman na direção da linha central (Rayleigh); b) mudanças nas intensidades e larguras de linhas; e c) mudanças no padrão vibracional do material se o mesmo sofrer mudança de fase estrutural.

De modo geral, o aumento da temperatura provocou efeitos nos espectros Raman, em uma dada amostra. Tais variações têm sua origem na mudança do volume do sólido (expansão térmica) e consequente espaçamento 

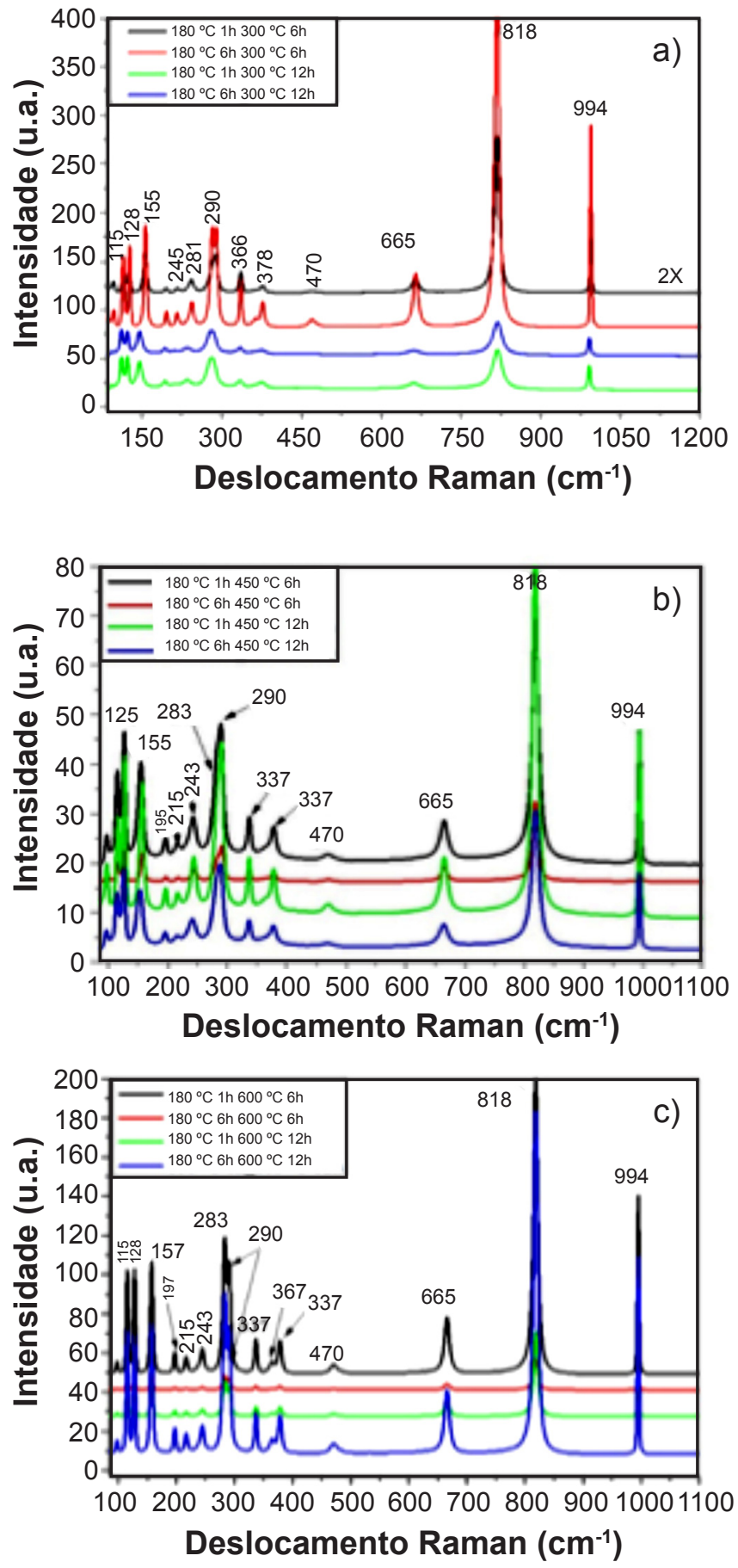

Figura 8: Espectros Raman das amostras de síntese hidrotérmica a $180{ }^{\circ} \mathrm{C}$ por 1 e $6 \mathrm{~h}$ e calcinadas por 6 e $12 \mathrm{~h}$ a: (a) $300{ }^{\circ} \mathrm{C}$; (b) $450{ }^{\circ} \mathrm{C}$; e (c) $600{ }^{\circ} \mathrm{C}$.

[Figure 8: Raman spectra of the samples from hydrothermal synthesis at $180^{\circ} \mathrm{C}$ for 1 and $6 \mathrm{~h}$ and calcined for 6 and $12 \mathrm{~h} \mathrm{at}$ : (a) $300{ }^{\circ} \mathrm{C}$; (b) $450{ }^{\circ} \mathrm{C}$; and (c) $600{ }^{\circ} \mathrm{C}$.]

interatômico, acarretando mudança na amplitude vibracional de cada átomo em torno da sua posição de equilíbrio [49]. Outro fato a se destacar são as alterações acompanhadas nos espectros de FTIR comparadas com as alterações discretas no espectro de Raman. Esta diferença entre os resultados de FTIR e Raman pode ser explicado considerando os efeitos de divisão longitudinal-transversal. Como o $\mathrm{MoO}_{3}$ pertence ao grupo $\mathrm{D}_{2 \mathrm{~h}}$, não existem modos vibracionais ativos para infravermelho e Raman simultaneamente. Assim os espectros de infravermelho foram mais influenciados pelas mudanças no material após o tratamento térmico.

Caracterização morfológica: as micrografias dos produtos formados conforme as variações de tempo de síntese hidrotérmica e temperatura de calcinação encontram-se na Fig. 9. Na Fig. 9A é possível identificar estruturas hexagonais características da fase $\mathrm{h}-\mathrm{MoO}_{3}$, como também formação de camadas características da fase $\alpha-\mathrm{MoO}_{3}$, confirmando os dados de difração expostos anteriormente à cerca da mistura de fases nas sínteses a $300{ }^{\circ} \mathrm{C}$. O aumento do tempo de calcinação favoreceu o crescimento das partículas em forma de microplacas. Dessa forma, o h- $\mathrm{MoO}_{3}$ foi formado em baixas temperaturas de síntese e aparentemente cresceu em tamanho e transformou para estrutura em camadas com a elevação da temperatura de calcinação. Este crescimento anisotrópico sob condições hidrotérmicas se deve a vários fatores, como características intrínsecas da estrutura, precursores, ativação energética do exterior, bem como a pressão autógena [50]. Na Fig. 9B verifica-se um aspecto morfológico lamelar característicos da fase $\alpha-\mathrm{MoO}_{3}$ com distribuição heterogênea de tamanho apresentada pelas partículas, além da presença de pequenos agregados formados a partir do aumento de temperatura no tratamento térmico das amostras. Na Fig. 9C observa-se que a morfologia das partículas em sua maioria apresentase uniforme, dando aspecto de pequenas placas. À medida que o tempo e temperatura de calcinação aumentaram, os cristalitos tenderam a se agregar e promover um rápido crescimento de partículas. Por isso, o tamanho de cristalito na escala nanométrica é de difícil controle para sínteses de $\alpha-\mathrm{MoO}_{3}$. Esses concordam com os resultados de DRX.

Os valores de energia de band gap (Fig. 10 e Tabela II) encontraram-se no intervalo de 2,74 e 3,33 eV, demostrando o potencial do trióxido de molibdênio para aplicação na fotocatálise heterogênea. Óxidos semicondutores com band gap nessa faixa são propícios a fotocatálise heterogênea, tanto com fonte de irradiação visível ou ultravioleta [16]. Observou-se que os óxidos calcinados a $600{ }^{\circ} \mathrm{C}$ apresentaram redução no valor de band gap em relação aos calcinados a $450{ }^{\circ} \mathrm{C}$. O aumento da temperatura de calcinação pode favorecer a formação de vacâncias de oxigênio na estrutura cristalina do $\mathrm{MoO}_{3}$, que por sua vez geram um defeito acima da banda de valência do $\mathrm{MoO}_{3}$ resultando na redução de gap [51].

Área superficial pelo método BET: com base nos resultados, Tabela III, observou-se que os maiores valores de área superficial foram encontrados em tempo de reação hidrotérmica de $1 \mathrm{~h}$ com tratamento térmico a $600{ }^{\circ} \mathrm{C}$. Isso comprovou que o tempo de reação tem influência significativa sobre a área superficial, como já relatado na literatura [52]. Os óxidos não calcinados (entradas 1 e 2) possuíram baixa área superficial, sendo que destes $\mathrm{o} \mathrm{MoO}_{3}$ obtido com $6 \mathrm{~h}$ de reação hidrotérmica apresentou área superficial de $9,5 \mathrm{~m}^{2} \cdot \mathrm{g}^{-1}$ (entrada 2). Esta área foi inferior à do óxido obtido nas mesmas condições, só que com $1 \mathrm{~h}$ de reação. Neste caso, a área de 


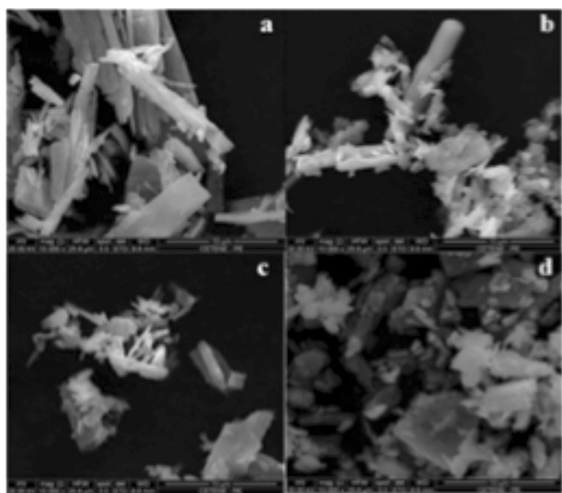

A)

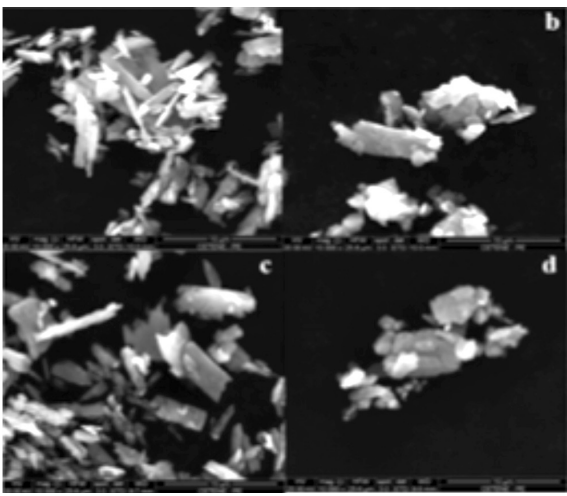

B)

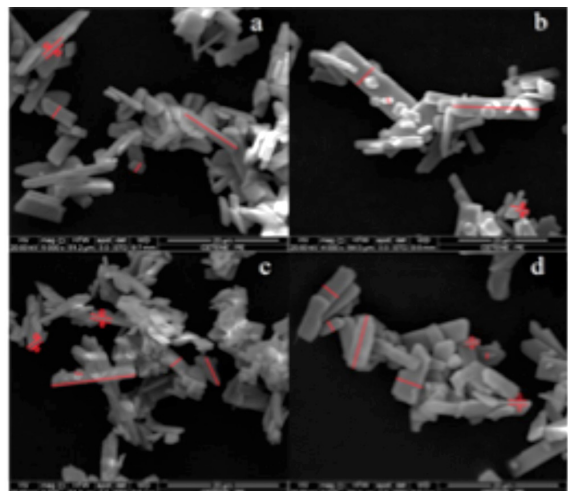

C)

Figura 9: Imagens de MEV das amostras de $\mathrm{MoO}_{3}$ sintetizadas a $180^{\circ} \mathrm{C}$ por $1 \mathrm{~h}$ (a) e $6 \mathrm{~h}$ (b) - calcinadas por $6 \mathrm{~h}$, e por $1 \mathrm{~h}(\mathrm{c})$ e $6 \mathrm{~h}(\mathrm{~d})$ calcinadas por $12 \mathrm{~h}$ a: (A) $300{ }^{\circ} \mathrm{C}$; (B) $450{ }^{\circ} \mathrm{C}$; e (C) $600{ }^{\circ} \mathrm{C}$.

[Figure 9: SEM images of the samples $\mathrm{MoO}_{3}$ synthesized at $180^{\circ} \mathrm{C}$ for $1 \mathrm{~h}(\mathrm{a})$ and $6 \mathrm{~h}(\mathrm{~b})$ - calcined for $6 \mathrm{~h}$, and for $1 \mathrm{~h}(\mathrm{c})$ and $6 \mathrm{~h}(\mathrm{~d})$ calcined for $12 \mathrm{~h}$ at: (A) $300^{\circ} \mathrm{C}$; (B) $450{ }^{\circ} \mathrm{C}$; and (C) $\left.600{ }^{\circ} \mathrm{C}.\right]$
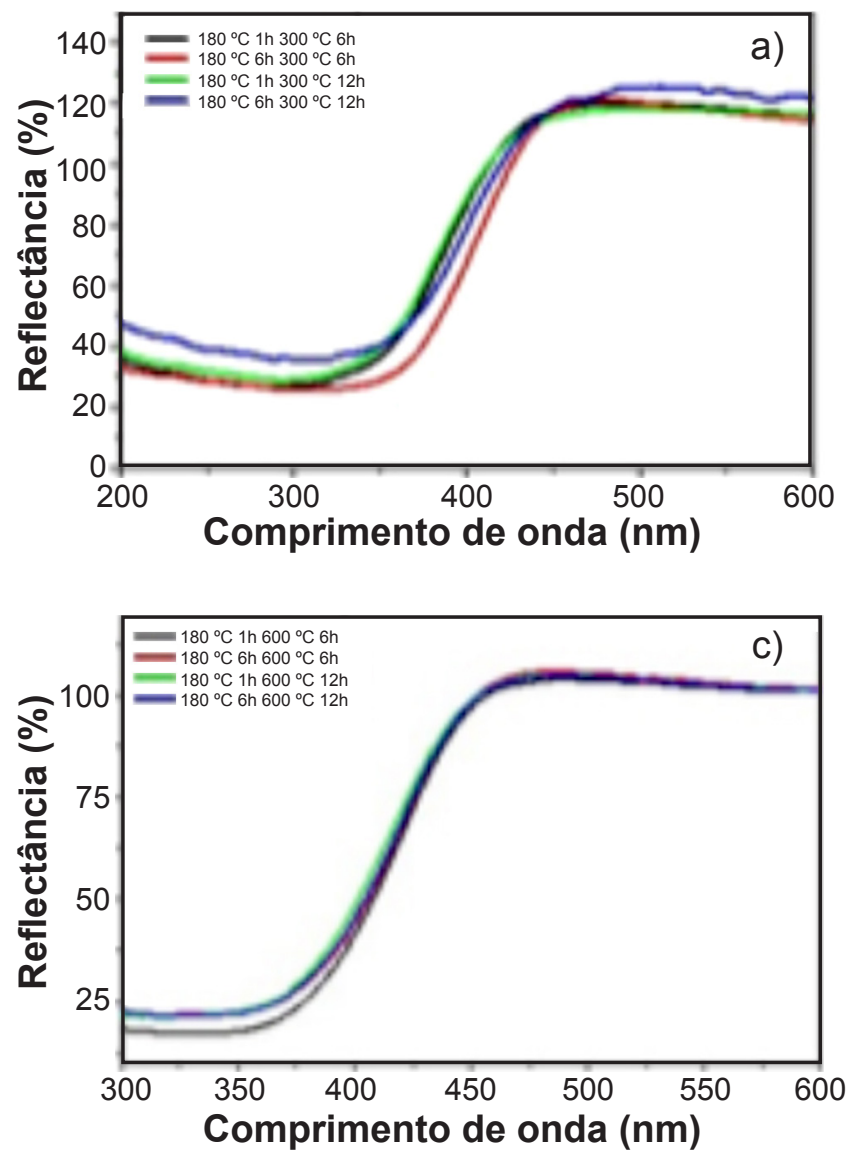

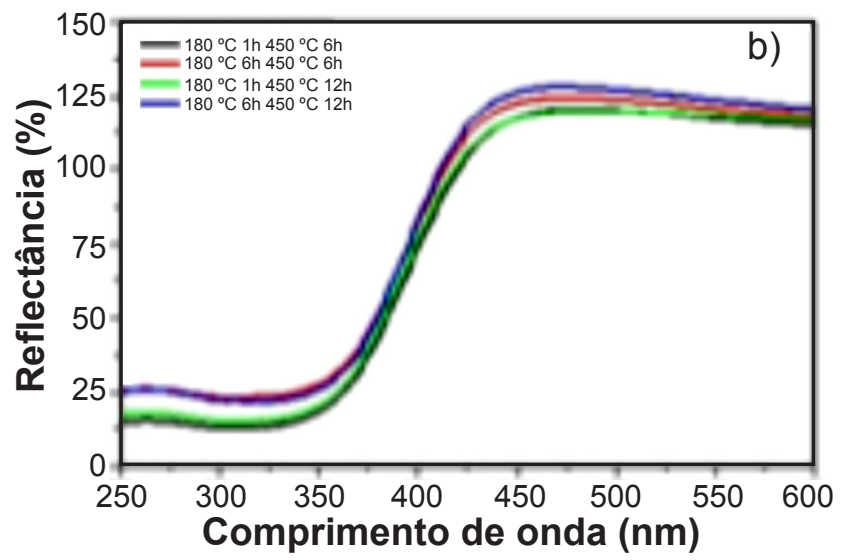

Temperatura de calcinação $\left({ }^{\circ} \mathrm{C}\right)$

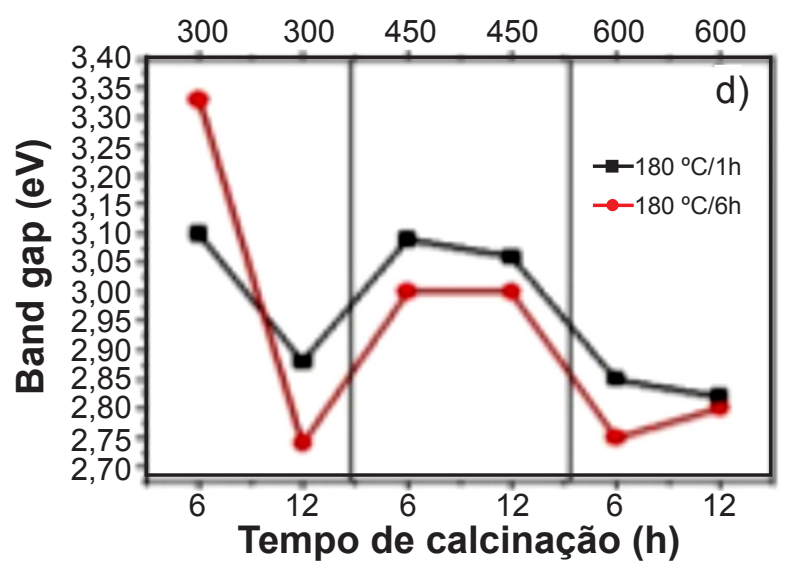

Figura 10: Espectros de reflectância difusa das amostras de $\mathrm{MoO}_{3}$ sintetizadas a $180{ }^{\circ} \mathrm{C}$ por 1 e 6 h e calcinadas a 300,450 e $600{ }^{\circ} \mathrm{C}$ por 6 e $12 \mathrm{~h}$ (a-c) e valores de energia de band gap dos pós de $\mathrm{MoO}_{3}(\mathrm{~d})$.

[Figure 12: Diffuse reflectance spectra of $\mathrm{MoO}_{3}$ samples synthesized at $180{ }^{\circ} \mathrm{C}$ for 1 and $6 \mathrm{~h}$ and calcined at 300,450 and $600{ }^{\circ} \mathrm{C}$ for 6 and $12 \mathrm{~h}(\mathrm{a}-\mathrm{c})$, and values of band gap energy of $\mathrm{MoO}_{3}$ powders $\left.(d).\right]$

$30,7 \mathrm{~m}^{2} \cdot \mathrm{g}^{-1}$ (entrada 1) foi relativa a um material amorfo, sem estrutura definida. Os óxidos obtidos mediante calcinação a $300{ }^{\circ} \mathrm{C}$ (entradas 3 a 6) apresentaram área superficial que variaram de 38,8 a 44,0 $\mathrm{m}^{2} \cdot \mathrm{g}^{-1}$. Neste caso, observou-se que os óxidos obtidos com $1 \mathrm{~h}$ de reação hidrotérmica apresentaram menor área superficial, $\sim 39,0 \mathrm{~m}^{2} \cdot \mathrm{g}^{-1}$ (entradas 3 e 5). Os óxidos obtidos com $6 \mathrm{~h}$ de aquecimento hidrotérmico apresentaram maior área, $40,5 \mathrm{~m}^{2} \cdot \mathrm{g}^{-1}$ (entrada 4) e $44,0 \mathrm{~m}^{2} \cdot \mathrm{g}^{-1}$ (entrada 6). Esse resultado mostrou o efeito do tempo de síntese e de calcinação, que pode resultar em óxidos com estrutura mais bem definida. Os óxidos obtidos após calcinação a $450{ }^{\circ} \mathrm{C}$ (entradas 7 a 10) apresentaram 
Tabela II - Valores de energia de band gap dos pós de $\mathrm{MoO}_{3}$. [Table II - Band gap energy values of $\mathrm{MoO}_{3}$ powders.]

\begin{tabular}{cccccc}
\hline $\begin{array}{c}\text { Reação } \\
\text { hidrotérmica }\end{array}$ & Calcinação & $\begin{array}{c}\text { Band gap } \\
(\mathrm{eV})\end{array}$ & $\begin{array}{c}\text { Reação } \\
\text { hidrotermica }\end{array}$ & Calcinação & $\begin{array}{c}\text { Band gap } \\
(\mathrm{eV})\end{array}$ \\
\hline \multirow{3}{*}{$180^{\circ} \mathrm{C} / 1 \mathrm{~h}$} & $300{ }^{\circ} \mathrm{C} / 6 \mathrm{~h}$ & 3,10 & & $300{ }^{\circ} \mathrm{C} / 6 \mathrm{~h}$ & 3,33 \\
& $300{ }^{\circ} \mathrm{C} / 12 \mathrm{~h}$ & 2,88 & & $300^{\circ} \mathrm{C} / 12 \mathrm{~h}$ & 2,74 \\
& $450{ }^{\circ} \mathrm{C} / 6 \mathrm{~h}$ & 3,09 & & $450{ }^{\circ} \mathrm{C} / 6 \mathrm{~h}$ & 3,00 \\
& $450{ }^{\circ} \mathrm{C} / 12 \mathrm{~h}$ & 3,06 & $180{ }^{\circ} \mathrm{C} / 6 \mathrm{~h}$ & $450{ }^{\circ} \mathrm{C} / 12 \mathrm{~h}$ & 3,00 \\
& $600{ }^{\circ} \mathrm{C} / 6 \mathrm{~h}$ & 2,85 & & $600{ }^{\circ} \mathrm{C} / 6 \mathrm{~h}$ & 2,75 \\
& $600{ }^{\circ} \mathrm{C} / 12 \mathrm{~h}$ & 2,82 & & $600^{\circ} \mathrm{C} / 12 \mathrm{~h}$ & 2,80 \\
\hline
\end{tabular}

Tabela III - Resultados da análise textural dos óxidos de $\mathrm{MoO}_{3}$. [Table III - Results of textural analysis of $\mathrm{MoO}_{3}$ oxides.]

\begin{tabular}{|c|c|c|c|c|c|}
\hline Entrada & $\begin{array}{c}\text { Reação } \\
\text { hidrotérmica }\end{array}$ & Calcinação & $\begin{array}{l}\text { Área superficial } \\
\qquad\left(\mathrm{m}^{2} / \mathrm{g}\right)\end{array}$ & $\begin{array}{l}\text { Volume de poro } \\
\qquad\left(\mathrm{cm}^{3} / \mathrm{g}\right)\end{array}$ & $\begin{array}{c}\text { Tamanho de } \\
\text { poro }(\AA)\end{array}$ \\
\hline 1 & $180^{\circ} \mathrm{C} / 1 \mathrm{~h}$ & - & 30,7490 & 0,087640 & 93,379 \\
\hline 2 & $180{ }^{\circ} \mathrm{C} / 6 \mathrm{~h}$ & - & 9,5541 & 0,008404 & 37,405 \\
\hline 3 & $180^{\circ} \mathrm{C} / 1 \mathrm{~h}$ & $300{ }^{\circ} \mathrm{C} / 6 \mathrm{~h}$ & 39,4563 & 0,044782 & 51,349 \\
\hline 4 & $180{ }^{\circ} \mathrm{C} / 6 \mathrm{~h}$ & $300{ }^{\circ} \mathrm{C} / 6 \mathrm{~h}$ & 40,5978 & 0,043987 & 50,058 \\
\hline 5 & $180{ }^{\circ} \mathrm{C} / 1 \mathrm{~h}$ & $300{ }^{\circ} \mathrm{C} / 12 \mathrm{~h}$ & 38,8910 & 0,073724 & 67,575 \\
\hline 6 & $180^{\circ} \mathrm{C} / 6 \mathrm{~h}$ & $300{ }^{\circ} \mathrm{C} / 12 \mathrm{~h}$ & 44,0805 & 0,056238 & 52,871 \\
\hline 7 & $180{ }^{\circ} \mathrm{C} / 1 \mathrm{~h}$ & $450{ }^{\circ} \mathrm{C} / 6 \mathrm{~h}$ & 39,2595 & 0,051134 & 50,1987 \\
\hline 8 & $180{ }^{\circ} \mathrm{C} / 6 \mathrm{~h}$ & $450{ }^{\circ} \mathrm{C} / 6 \mathrm{~h}$ & 32,9211 & 0,036734 & 44,1183 \\
\hline 9 & $180^{\circ} \mathrm{C} / 1 \mathrm{~h}$ & $450{ }^{\circ} \mathrm{C} / 12 \mathrm{~h}$ & 53,1137 & 0,062951 & 46,6351 \\
\hline 10 & $180{ }^{\circ} \mathrm{C} / 6 \mathrm{~h}$ & $450^{\circ} \mathrm{C} / 12 \mathrm{~h}$ & 30,1362 & 0,033632 & 44,0973 \\
\hline 11 & $180{ }^{\circ} \mathrm{C} / 1 \mathrm{~h}$ & $600{ }^{\circ} \mathrm{C} / 6 \mathrm{~h}$ & 53,9676 & 0,045421 & 36,1102 \\
\hline 12 & $180{ }^{\circ} \mathrm{C} / 6 \mathrm{~h}$ & $600{ }^{\circ} \mathrm{C} / 6 \mathrm{~h}$ & 48,9480 & 0,040806 & 35,6100 \\
\hline 13 & $180^{\circ} \mathrm{C} / 1 \mathrm{~h}$ & $600{ }^{\circ} \mathrm{C} / 12 \mathrm{~h}$ & 54,1635 & 0,045752 & 36,1987 \\
\hline 14 & $180{ }^{\circ} \mathrm{C} / 6 \mathrm{~h}$ & $600^{\circ} \mathrm{C} / 12 \mathrm{~h}$ & 44,4488 & 0,037532 & 36,1482 \\
\hline
\end{tabular}

área superficial que variaram de 30,1 a 53,1 m². $\mathrm{g}^{-1}$. $\mathrm{O} \mathrm{MoO}_{3}$ obtido após $12 \mathrm{~h}$ de calcinação está entre os óxidos calcinados que apresentou menor $\left(30,3 \mathrm{~m}^{2} \cdot \mathrm{g}^{-1}\right.$, entrada 10$)$ e maior $\left(53,1 \mathrm{~m}^{2} \cdot \mathrm{g}^{-1}\right.$, entrada 9) área superficial. Não foi observado neste caso nenhuma relação direta da área superficial com as condições de síntese ou calcinação. Os óxidos obtidos após calcinação a $600^{\circ} \mathrm{C}$ (entradas 11 a 14) apresentaram área superficial que variaram de 44,4 a $54,1 \mathrm{~m}^{2} \cdot \mathrm{g}^{-1}$. Neste caso, foi possível observar que a área superficial dos óxidos obtidos com $1 \mathrm{~h}$ de reação hidrotérmica (entradas $11 \mathrm{e}$ 13) foram os que apresentaram maior área superficial. Para volume e tamanho de poros, não foi encontrada relação direta com os parâmetros de síntese.

Avaliação da atividade fotocatalítica em efluente sintético: em todos os testes catalíticos a temperatura foi mantida na faixa de $25 \pm 2{ }^{\circ} \mathrm{C}$, pois segundo [53] a taxa de degradação aumenta com o aumento da temperatura, sem que este parâmetro influencie significativamente o processo fotocatalítico, haja visto que a ativação fotônica em sistemas fotocatalíticos não necessitam de aquecimento [54].
Para avaliar o efeito isolado de adsorção pelo $\mathrm{MoO}_{3}$, foram realizados ensaios na ausência de luz. A escolha das condições experimentais foram as mesmas estabelecidas para os testes fotocatalíticos. Os resultados obtidos apresentaram baixos índices de adsorção, que podem estar associados aos parâmetros utilizados, componentes presentes no efluente, bem como a baixa interação do efluente com o catalisador. Desse modo, os processos de fotocatálise neste trabalho não sofreram influência de processos de adsorção. Na Fig. 11a têm-se os resultados da degradação do efluente sintético com as amostras de $\mathrm{MoO}_{3}$ calcinados a $300{ }^{\circ} \mathrm{C}$; foram aplicadas na fotodegradação do efluente sintético por $2 \mathrm{~h}$, na qual a taxa de degradação máxima chegou a $43 \%$. As variações de síntese e tratamento térmico do $\mathrm{MoO}_{3}$ não produziram grandes alterações nas porcentagens de degradação; apenas uma das amostras mostrou baixo rendimento, com cerca de 35\% degradação, Fig. 11a. Na Fig. 11b têm-se os resultados da degradação do efluente sintético com as amostras de $\mathrm{MoO}_{3}$ calcinadas a $450{ }^{\circ} \mathrm{C}$. Neste caso, a taxa de degradação foi inferior às calcinadas 

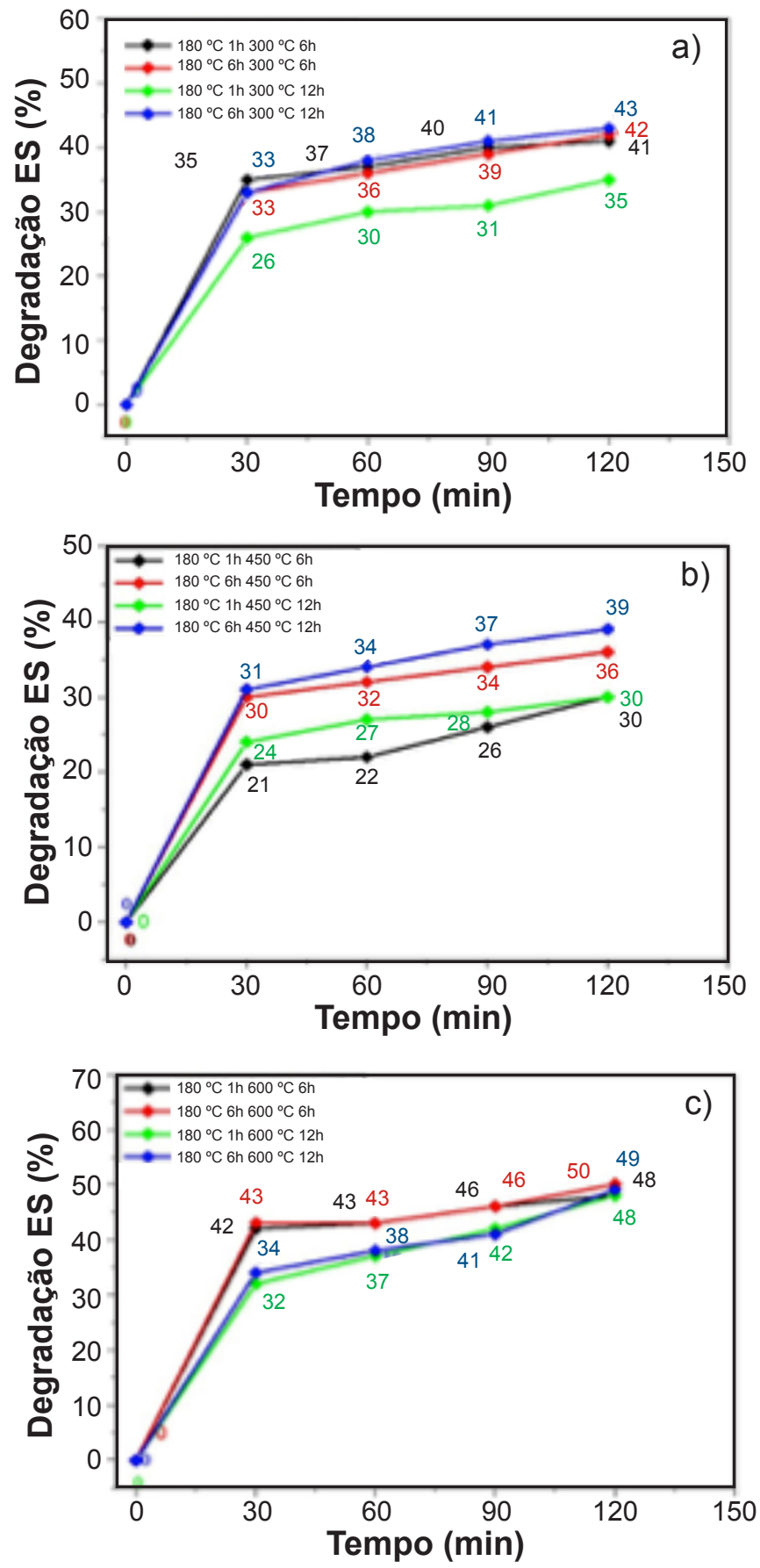

Figura 11: Porcentagem de degradação do efluente sintético (ES) em função do tempo de irradiação com o catalisador $\mathrm{MoO}_{3}$ sintetizado a $180^{\circ} \mathrm{C}$ por 1 e $6 \mathrm{~h}$ e calcinado por 6 e $12 \mathrm{~h}$ a: (a) $300^{\circ} \mathrm{C}$; (b) $450{ }^{\circ} \mathrm{C}$; e (c) $600{ }^{\circ} \mathrm{C}$.

[Figure 11: Percentage of degradation of the synthetic effluent (ES) as a function of irradiation time with the $\mathrm{MoO}_{3}$ catalyst synthesized at $180{ }^{\circ} \mathrm{C}$ for 1 and $6 \mathrm{~h}$ and calcined for 6 and $12 \mathrm{~h}$ at: (a) $300{ }^{\circ} \mathrm{C}$; (b) $450{ }^{\circ} \mathrm{C}$; and (c) $600{ }^{\circ} \mathrm{C}$.]

a $300{ }^{\circ} \mathrm{C}$, com no máximo $39 \%$ de degradação do efluente. $\mathrm{O}$ desempenho dos óxidos calcinados a $300{ }^{\circ} \mathrm{C}$ (Fig. 11a) em relação aos de $450^{\circ} \mathrm{C}$ (Fig. 11b) pode ser explicado pela presença de mistura das fases $\mathrm{h}-\mathrm{MoO}_{3}$ e $\alpha-\mathrm{MoO}_{3}$, no qual estudos demostram a elevada eficiência fotocatalítica da fase metaestável hexagonal [15, 17, 43, 49, 55]. Além disso, o baixo rendimento dos óxidos tratados a $450{ }^{\circ} \mathrm{C}$ pode estar relacionado aos valores elevados de energia de gap. Na Fig. 11c têm-se os resultados da degradação do efluente sintético com o $\mathrm{MoO}_{3}$ tratado a $600{ }^{\circ} \mathrm{C}$. Os óxidos obtidos nessa temperatura apresentaram o melhor desempenho fotocatalítico entre todos os óxidos sintetizados, degradando até $50 \%$ do efluente em 2 h de reação.

Comparando os óxidos calcinados em diferentes temperaturas, $\mathrm{o} \mathrm{MoO}_{3}$ calcinado a $600{ }^{\circ} \mathrm{C}$ demonstrou apresentar maior cristalinidade (Fig. 3c), morfologia mais bem definida (Fig. 9C) e menores valores de band gap, 2,75 a 2,85 eV (Tabela II). Neste caso, acredita-se que os baixos valores de energia de band gap seja o principal fator que influenciou a alta atividade catalítica, haja visto que o $\mathrm{MoO}_{3}$ obtido nesta temperatura apresentou-se em uma única fase, a ortorrômbica. Comparando o $\mathrm{MoO}_{3}$ obtido a 300 e $450{ }^{\circ} \mathrm{C}$, o melhor resultado catalítico foi o obtido em menor temperatura. Como os valores de band gap foram muito próximos, a presença da fase hexagonal na mistura de óxidos foi preponderante em relação à fase ortorrômbica. Mas, comparando o $\mathrm{MoO}_{3}$ obtido a 300 e $600{ }^{\circ} \mathrm{C}$, o melhor resultado catalítico foi o $\mathrm{MoO}_{3}$ obtido a $600{ }^{\circ} \mathrm{C}$. No entanto, comparando as diferentes fases, acredita-se que os baixos valores de band gap do $\mathrm{MoO}_{3}$ na fase ortorrômbica superaram os altos valores de band gap do $\mathrm{MoO}_{3}$ na fase hexagonal.

De modo geral, a atividade fotocatalítica do $\mathrm{MoO}_{3} \mathrm{em}$ efluente sintético apresentou bons resultados. Segundo [56], testes realizados em efluentes sanitários com os catalisadores de $\mathrm{TiO}_{2}, \mathrm{Nb}_{2} \mathrm{O}_{5}$ e $\mathrm{TiO}_{2}-\mathrm{Nb}_{2} \mathrm{O}_{5}$ sob radiação visível apresentaram entre 34 a $40 \%$ de degradação em 360 min. Outros trabalhos [57] detalham o desempenho do $\mathrm{TiO}_{2}$ como catalisador na degradação do 4-isopropilfenol, componente presente em efluente industrial, no qual os índices de degradação atingiram aproximadamente $50 \%$ da concentração inicial. Em relação à aplicação do $\mathrm{MoO}_{3}$, Diao et al. [58] aplicaram o $\mathrm{MoO}_{3}$ obtido por calcinação na degradação do violeta de metila, obtendo em $2 \mathrm{~h}$ de reação $38 \%$ e $57 \%$ de descoloração para o óxido calcinado a 500 e $600{ }^{\circ} \mathrm{C}$, respectivamente. Chithambararaj et al. [59] aplicaram $\mathrm{o} \mathrm{MoO}_{3}$ na fase hexagonal na degradação do azul de metileno, obtendo $98 \%$ de descoloração no visível, $66 \%$ no UV e $39 \%$ no escuro. Ainda, Chithambararaj et al. [16] investigaram a atividade do $\mathrm{MoO}_{3}$ nas fases hexagonal e ortorrômbica na degradação do azul de metileno, obtendo $94 \%$ de descoloração para $\mathrm{o} \mathrm{MoO}_{3}$ na fase hexagonal e $13 \%$ para $\mathrm{MoO}_{3}$ na fase ortorrômbica. Esses resultados mostram que o $\mathrm{MoO}_{3}$ obtido nesse trabalho apresenta-se com grande potencial como fotocalisador, haja visto que neste trabalho foi simulado um ambiente com todas as condições reais de uma estação de resíduo de efluente têxtil, degradando até $50 \%$ do corante, condições diferentes dos artigos citados [16, 56-59].

Como descrito, foi investigado o efeito isolado de adsorção pelo $\mathrm{MoO}_{3}$, realizando ensaios na ausência de luz. Observou-se que os resultados obtidos apresentaram baixos índices de adsorção, o que pode estar associado aos parâmetros utilizados. Assim, acredita-se que os processos 
de fotocatálise neste trabalho não sofreram influência de processos de adsorção. Neste sentido, justifica o fato de não se ter encontrado relação do processo fotocatalítico com a área superficial, pois a reação fotocatalítica pode ocorrer a partir da geração de espécies cataliticamente ativas em solução. $\mathrm{O}$ efeito catalítico do $\mathrm{MoO}_{3}$ no processo reacional pode ter favorecido a elevação da taxa de radicais hidroxílicos (HO') formados, gerados mediante o processo de excitação/recombinação dos elétrons presentes na banda de valência para a banda de condução, após absorverem fótons com magnitude superior ao do band gap óptico (Fig. 10 e Tabela II). Na presença de espécies capturadores de elétrons $\left(\mathrm{O}_{2}\right)$, o processo resulta na formação de buracos $\left(\mathrm{h}^{+}\right)$ que oxidam as moléculas de água adsorvidas na superfície das nanopartículas, elevando assim a formação dos radicais hidroxílicos, que por serem altamente reativos atacam as cadeias carbônicas do corante, degradando-o $[60,61]$.

\section{CONCLUSÕES}

O método de síntese hidrotérmica usado neste trabalho mostrou-se eficiente para a formação de duas fases diferentes do $\mathrm{MoO}_{3}$ (hexagonal e ortorrômbico). As variáveis de tempo e temperatura aplicadas revelaram que reações hidrotérmicas a $180{ }^{\circ} \mathrm{C}$ ou inferiores favorecem a formação da fase $\mathrm{h}-\mathrm{MoO}_{3}$, enquanto o tratamento térmico a $450{ }^{\circ} \mathrm{C}$ favorece a formação da fase $\alpha-\mathrm{MoO}_{3}$ com homogeneidade morfológica, permitindo assim um controle de fase por meio da síntese hidrotérmica e calcinação. As caracterizações por DRX demonstraram a formação de mistura de fases e sua transformação em fase ortorrômbica com aumento da temperatura. As bandas vibracionais entre 1050 e $400 \mathrm{~cm}^{-1}$, bem como os picos situados em 994, 818 e $665 \mathrm{~cm}^{-1}$ nos espectros Raman, mostraram as interações do metal com o oxigênio. As estimativas calculadas das energias de band gap foram no intervalo de 2,74 a 3,33 eV. Os testes fotocatalíticos revelaram que o desempenho do $\mathrm{MoO}_{3}$ com duas fases cristalinas foi inferior ao da fase $\alpha-\mathrm{MoO}_{3}$, que apresentou os maiores índices de degradação, em torno de $50 \%$, durante 2 $\mathrm{h}$ de fotodegradação.

\section{AGRADECIMENTOS}

Os autores agradecem à Universidade Federal do Piauí (UFPI), à Lazule Jeans Ind Confecções de Teresina - Piauí, ao Centro de Tecnologias Estratégicas do Nordeste (CETENE) pelas análises de MEV e infravermelho e ao apoio financeiro do Conselho Nacional de Ciência e Tecnologia (CNPq), processo 304261/2009-2.

\section{REFERÊNCIAS}

[1] T. Lui, B. Li, Y. Hao, Z. Yao, Chem. Eng. J. 244 (2014) 382.

[2] M. Neamtu, P. Siminiceanu, I. Yediler, A. Kettrup, Dyes Pigm. 53 (2002) 93.

[3] K. Nagaveni, G. Sivalingan, G. Madras, Environ. Sci.
Technol. 38 (2004) 1600.

[4] X.Z. Li, H. Liu, H.J. Tong, Environ. Sci. Technol. 37 (2003) 3989.

[5] O. Legrini, E. Oliveros, A.M. Braun, Chem. Rev. 93 (1993) 671.

[6] C.P. Huang, C. Dong, Z. Tang, Waste Manage. 13 (1993) 361.

[7] R.W. Matthews, Water Res. 25 (1991) 1169.

[8] R.F.P. Nogueira, W.F. Jardim, Sol. Energy 56 (1996) 471.

[9] O. Bierwagen, Semicond. Sci. Technol. 30, 2 (2015) 24001.

[10] J. Kim, T. Sekiya, N. Miyokawa, N. Watanabe, K. Kimoto, K. Ide, Y. Toda, S. Ueda, N. Ohashi, H. Hiramatsu, H. Hosono, T. Kamiya, NPG Asia Mater. 9 (2017) e359.

[11] S.L. Jain, V.V.D.N. Prasad, B. Sain, Catal. Commun. 9 (2008) 499.

[12] N.A. Chernova, M. Roppolo, A.C. Dillon, M.S. Whittingham, J. Mater. Chem. 19 (2009) 2526.

[13] E. Comini, L. Yubao, Y. Brando, G. Sberveglieri, Chem. Phys. Lett. 407 (2005) 368.

[14] Y. Shen, R. Huang, Y. Cao, P.P. Wang, Mater. Sci. Eng. 172 (2010) 237.

[15] L. Zheng, Y. Xu, D. Jin, Y. Xie, J. Chem. Mater. 21 (2009) 5681.

[16] A. Chithambararaj, N.S. Sanjini, S. Velmathi, A. Chandra Bose, Phys. Chem. Chem. Phys. 15, 35 (2013) 14761.

[17] T. Mizushima, Y. Moriya, N.H.H. Phuc, H.O.N. Kakuta, Catal. Commun. 13 (2011) 10.

[18] J.B. Parise, E.M. McCarron, R. Von Dreele, J.A. Goldstone, J. Solid State Chem. 93 (1991) 193.

[19] E.M. McCarron, J.C. Calabrese, J. Solid State Chem. 91 (1991) 121.

[20] D. Liu, W.W. Lei, J. Hao, D.D. Liu, B.B. Liu, X. Wang, X.H. Chen, Q.L. Cui, G.T. Zou, J. Liu, S. Jiang, J. Appl. Phys. 105 (2009) 1.

[21] C.V. Ramana, C.M. Julien, Chem. Phys. Lett. 428 (2006) 114.

[22] F.F. Ferriera, T.G. Souza Cruz, M.C.A. Fantini, M.H. Tabacniks, C. Sandra, J. Morais, A. Siervo, R. Landers, A. Gorenstein, Solid State Ionics 357 (2000) 136.

[23] R.C. Ardenas, J. Torres, J.E. Alfonso, Thin Solid Films 478 (2005) 146.

[24] A. Abdellaoui, G. Lêvêque, A. Donnadieu, A. Bath, B. Ouchikhi, Thin Solid Films 304 (1997) 39.

[25] Y. Zhang, S. Kuai, Z. Wang, X. Hu, Appl. Surface Sci. 165 (2000) 56.

[26] A. Chithambararaj, A.C. Bose, J. Alloys Compd. 509 (2011) 8105.

[27] I.A. Castro, R.S. Datta, J.Z. Ou, A. Castellanos-Gomez, S. Sriram, T. Daeneke, K. Kalantar-Zade, Adv. Mater. 29, 40 (2017) 1701619.

[28] J. Mo, J.E. Hwang, J. Jegal, J. Kim, Dyes Pigm. 72 (2007) 240.

[29] A. Chithambararaj, D.B. Mathi, N.R. Yogamalar, A.C. Bose, Mater. Res. Express 2 (2015) 055004.

[30] C. Julien, A. Khelfa, O.M. Hussain, G.A. Nazri, J. 
Cryst. Growth 156 (1995) 235.

[31] G.A. Nazri, C. Julien, Solid State Ionics 53-56 (1992) 376.

[32] H.C. Zeng, J. Cryst. Growth 186 (1998) 393.

[33] K.J. Eda, J. Solid State Chem. 95 (1991) 64.

[34] J.V. Silveira, "Propriedades vibracionais de nanotubos e nanobastões de óxido de molibdênio", Diss. Mestr., Un. Federal Ceará (2010).

[35] I.R. Beattie, T.R. Gilson, J. Chem. Soc. A Inorg. Phys. 0 (1969) 2322.

[36] T. Xia, Q. Li, X. Liu, J. Meng, X.J. Cao, Phys. Chem. B 110 (2006) 2006.

[37] Y. Muraoka, J.C. Grenier, S. Petit, M. Pouchard, Solid State Sci. 1 (1999) 133.

[38] L.Q. Mai, B. Hu,W. Chen, Y.Y. Qi, C.S. Lao, R.S. Yang, Y. Dai, Z.L. Wang, Adv. Mater. 19 (2007) 3712.

[39] D. Chen, M. Liu, L. Yin, T. Li, Z. Yang, X. Li, B. Fan, H. Wang, R. Zhang, Z. Li, H. Xu, H. Lu. D. Yang, J. Sune, L. Gao, J. Mater. Chem. 21 (2011) 9332.

[40] L.G. Pereira, L.E.B. Soledade, J.M. Ferreira, S.J.G. Lima, V.J. Fernandes Jr, A.S. Araújo, C.A. Paskocima, E. Longo, M.R.C. Santos, A.G. Souza, I.M.G. Santos, J. Alloys Compd. 459 (2008) 377.

[41] R. Liang, H. Cao, D. Qian, Mater. Chem. Commun. 47 (2011)1305.

[42] S. Jiebing, J.X. Rui, J. Sol-Gel Sci. Technol. 27 (2003) 315 .

[43] Y. Mao, W. Li, X. Sun, Y. Ma, J. Xia, Y. Zhao, X. Lu, J. Gan, Z. Liu, J. Chen, P. Liu, Y. Tong, Cryst. Eng. Comm. 14 (2012) 1419.

[44] Q.P. Ding, H.B. Huang, J.F. Duan, S.G. Gong, X.N. Yang, Y.W. Du, J. Cryst. Growth 294 (2006) 304.

[45] X. Chen, W. Lei, D. Liu, J. Hao, Q. Cui, G. Zou, J.
Phys. Chem. 113 (2009) 21582.

[46] M.A. Py, K. Maschke, Phys. B+C 105 (1981) 370.

[47] A. Klinbumrung, T. Thongtem, S. Thongtem, J. Nanomater. 1 (2012) 1155.

[48] T. Siciliano, A. Tepore, E. Filippo, G. Micocci, M. Tepore, Mater. Chem. Phys. 114 (2009) 687.

[49] R. Murugan, A. Ghule, C. Bhongale, H. Chang, J. Mater. Chem. 10 (2000) 2157.

[50] Y.P. Fang, A.W. Xu, A.M. Qin, R.J. Yu, Cryst. Growth Des. 5 (2005) 1221.

[51] T.S. Sian, G.B. Reddy, Sol. Energy Mater. Sol. Cells 82 (2004) 375.

[52] Y.V. Kolen'ko, B.R. Churagulov, M. Kunst, L. Mazerolles, C. Colbeau-Justin, Appl. Catal. B Environ. 54 (2004) 51.

[53] M.A. Fox, M.T. Dulay, Chem. Rev. 93 (1993) 341.

[54] J.M. Herrmann, Catal. Today 53 (1999) 115.

[55] Y. Chen, C. Lu, L. Xu, Y. Ma, W. Hou, J. Zhu, Cryst. Eng. Comm. 12 (2010) 3740.

[56] V.S. Santana, N.R.C.F. Machado, Acta Scientiarum 24, 6 (2002) 1681.

[57] Y. Mokhbi, M. Korichi, H.M. Sidrouhou, K. Chaouche, Energy Procedia 50 (2014) 559.

[58] Z. Diao, F.-L. Kwong, J. Li, J. Lian, K.-T. Lai, D.H.L. Ng, Environ. Eng. Sci. 29 (2012) 860.

[59] A. Chithambararaj, N.S. Sanjini, A.C. Bose, S. Velmathi, Catal. Sci. Technol. 3 (2013) 1405.

[60] J. Zhang, P. Zhou, J. Liub, J. Yu, Phys. Chem. Chem. Phys. 16, 38 (2014) 20382.

[61] J. Li, X. Xu, X. Liu, C. Yu, D. Yan, Z. Sun, L. Pan, J. Alloys Compd. 679 (2016) 454.

(Rec. 09/08/2017, Rev. 28/10/2017, 22/02/2018, Ac. $08 / 03 / 2018)$ 